Research Article

\title{
The Effect of miR-520b on Macrophage Polarization and T Cell Immunity by Targeting PTEN in Breast Cancer
}

\author{
Qin Zhu, ${ }^{1}$ Jiaqi Yuan, ${ }^{1}$ Yuqiong $\mathrm{He},{ }^{1}$ and $\mathrm{Yu} \mathrm{Hu} \mathbb{D}^{1,2}$ \\ ${ }^{1}$ Department of General Surgery, Xiangya Hospital, Central South University, Changsha 410008, China \\ ${ }^{2}$ Clinical Research Certer for Breast Cancer in Hunan Province, Changsha 410008, China \\ Correspondence should be addressed to Yu Hu; huyula99@163.com
}

Received 23 July 2021; Revised 31 August 2021; Accepted 9 September 2021; Published 6 October 2021

Academic Editor: Reem Saleh

Copyright $\odot 2021$ Qin Zhu et al. This is an open access article distributed under the Creative Commons Attribution License, which permits unrestricted use, distribution, and reproduction in any medium, provided the original work is properly cited.

Background. Breast cancer is the most common cancer in women. miR-520b had binding sites with PTEN through the bioinformatics prediction. But few studies have been conducted on $m i R-520 b$ and PTEN in breast cancer. We aimed to explore the effect of miR-520b and PTEN on breast cancer and the mechanisms involved. Methods. Clinical samples of breast cancer were collected. Bioinformatics analysis was performed to screen the differentially expressed miRNAs. CD4 T cells and CD8 T cells were cocultured with MCF-7 cells in the Transwell system. Moreover, MCF-7 cells and M0 macrophage cocultured cell lines were constructed. qRT-PCR, IF, western blot, flow cytometry, and ELISA were performed to detect related factors expression. Starbase and dual-luciferase reporter assay verified the binding of miR-520b to PTEN. The tumor formation model was established to study $m i R-520 b$ and PTEN effects in vivo. Results. The differentially expressed miR-520b was screened via miRNAs sequencing and cell verification. $m i R-520 b$ expression was high, $P T E N$ was low in tumor tissues, T cells and NK cells were inhibited, and macrophages were transformed into M2 type, promoting immune escape. In addition, $m i R-520 b$ bound to PTEN. Then, splenic CD4 T cells and CD8 T cells were successfully sorted. During CD4 T cell differentiation to Th1 and Treg, Th1 was inhibited, and Treg was activated. We found the polarization of macrophages was related to breast cancer. The proportion of CD206 cells increased and CD68 cells decreased in the miR-520b mimics group compared with the mimic NC group. Compared with the inhibitor NC group, the proportion of CD206 cells decreased, and CD68 cells increased in the miR-520b inhibitor group. In vivo experiments showed that miR-520b inhibitor inhibited tumor growth and promoted PTEN expression. The proportion of CD3, CD4, CD8, NK1.1, CD4+IFN $\gamma$, and CD68 cells increased, while FOXP3 and CD206 cells decreased in the miR-520b inhibitor group compared with the inhibitor NC group. However, the proportion of CD3, CD4, CD8, NK1.1, CD4+IFN $\gamma$, and CD68 cells decreased, while FOXP3 and CD206 cells increased after the addition of siPTEN. Conclusions. miR-520b inhibited PTEN and aggravated breast tumors. $m i R-520 b$ inhibitor enhanced CD4 and CD8 cell populations in the tumor immune microenvironment and inhibited tumor growth.

\section{Introduction}

Breast cancer is the most common cancer in women and the second leading cause of cancer-related deaths [1]. Through epidemiological and clinical studies, the incidence of breast cancer is still on the rise [2]. Breast cancer is a heterogeneous disease whose occurrence and development are mostly related to estrogen, and tumor stratification is crucial for better clinical outcomes [3-5]. At present, breast cancer treatment mainly consists of surgical resection, chemotherapy, combined therapy of hormone drugs, and molecular targeting to relieve symptoms and prolong the life of patients [6]. While alleviating cancer, these treatments also greatly affect the patients' quality of life and impose a heavy burden on their families. Therefore, seeking a new efficient and low-cost treatment has become an urgent problem for us.

microRNAs (miRNAs) are 21-25 long nucleotides that have significantly influenced gene expression [7]. Recently, miRNAs have shown potential as novel biomarkers for many cancers, including breast cancer $[7,8]$. miRNAs are involved in the metastatic cascade of breast cancer $[9,10]$. A previous study revealed $m i R-520 b$ is upregulated in cancer tissues of 
breast cancer patients, and the level of $m i R-520 b$ is inversely related to the metastatic potential of breast cancer cells [11]. $m i R-520 b$ could also promote breast cancer stemness through the Hippo/YAP signaling pathway [12]. These studies suggest that $m i R-520 b$ may be a potential diagnostic biomarker and therapeutic target for breast cancer. Interestingly, we found that miR-520b had binding sites with PTEN through the bioinformatics prediction. But few studies have been conducted on $m i R-520 b$ and PTEN in breast cancer. Therefore, we wanted to explore the role of $m i R-520 b$ and PTEN in breast cancer.

Phosphatase and tensin homolog (PTEN) are tumor suppressors with growth and survival regulatory functions that directly antagonize the PI3K/AKT pathway [13]. PTEN gene can affect a series of biological processes of $\mathrm{T}$ lymphocytes, especially in growth, development, proliferation, differentiation, activation, and cytokine secretion $[14,15]$. However, PTEN gene changes often lead to abnormal $\mathrm{T}$ cell responses and even autoimmune diseases and T cell malignancies $[16,17]$. T cell-mediated immunotherapy is a promising approach to cancer therapy, and PTEN deficiency promotes resistance to $\mathrm{T}$ cell-mediated immunotherapy [18]. Kishimoto's study showed that the PTEN gene could lead to a prominent decrease in the number of natural killer $\mathrm{T}$ cells and further lead to the deterioration of immunosuppression [19]. In addition, PTEN can regulate CD4 T cells, CD8 T cells, and Treg cells [20]. Therefore, it needs to understand PTEN regulatory signals in breast cancer further.

In this study, we screened for $m i R-520 b$ with significant differences in breast cancer by bioinformatics analysis. In addition, miR-520b could aggravate immunosuppression and accelerate breast cancer progression through PTEN. The results of this study confirmed the importance of $m i R-520 \mathrm{~b} /$ $P T E N$ as a potential biomarker for breast cancer treatment.

\section{Materials and Methods}

2.1. Clinical Tissue Samples. Breast tumor and tumor-adjacent tissue were collected from patients diagnosed with triple negative breast cancer by iconography, serology, or histopathology in the Xiangya Hospital, Central South University, from November 2020 to April 2021. Table 1 shows the demographic characteristics of patients with triple negative breast cancer $(n=30)$. We had obtained the subjects' written informed consent before the study and received approval from the Medical Ethics Committee of Xiangya Hospital (AF/SQ202104792).

2.2. Bioinformatics Analysis. The data were obtained from the GEO database GSE45666. The clinical samples were divided into breast cancer group $(n=101)$ and normal group $(n=15)$. All data were normalized. $R$ package limma screened differentially expressed miRNAs. The selection criteria were $|\log \mathrm{FC}|>1[21]$ and $P<0.05$ [22], and the volcano map and heatmap were drawn. Then, we used Diana to predict miRNA and found that hsa-miR-520b was upregulated in breast cancer and interacted with PTEN. The
TABle 1: Demographic characteristics of patients with triple negative breast cancer.

\begin{tabular}{lc}
\hline Characteristics & Cases $(n=30)$ \\
\hline Age $($ mean \pm SD) & $49.83 \pm 10.90$ \\
Tumor site $(n)$ & \\
Left side & 15 \\
Right side & 13 \\
Both sides & 2 \\
Lymph node $(\mathrm{cm})$ & $0.27 \pm 0.20$ \\
T staging $(n)$ & \\
N0 & 0 \\
N1 & 8 \\
N2 & 2 \\
N3 & 20 \\
Receptor expression $( \pm)$ & \\
ER & - \\
PR & - \\
HER2 & - \\
\hline
\end{tabular}

SD, standard deviation; ER, estrogen receptor; $\mathrm{PR}$, progesterone receptor; HER2, human epidermal growth factor receptor 2 .

network map of hsa-miR-520b and PTEN was plotted by Cytoscape. Diana (http://diana.imis.athena-innovation.gr/ DianaTools/index.php? $r=$ microT_CDS/index) has a score for each pair, and the selection score was set as 0.75 .

2.3. Cell Culture and Treatment. Human mammary epithelial cell line MCF-10A and human breast cancer cell line MCF-7 were purchased from the American Type Culture Collection (ATCC, Virginia, USA). MCF-10A cells were cultured in DMEM high glucose with $10 \%$ fetal bovine serum (FBS) and 1\% penicillin/streptomycin. MCF-7 cells were cultured in DMEM high glucose with 20\% FBS and 1\% penicillin/streptomycin/amphotericin. All cells were cultured in an incubator at $37^{\circ} \mathrm{C}$ with $5 \% \mathrm{CO}_{2}$. According to the instructions, $m i R-520 b$ mimics, $m i R-520 b$ inhibitor and its corresponding negative control mimic NC, and inhibitor NC were transfected into the cells using Lipofectamine 3000 reagent (Thermo Fishier Scientific, USA) for subsequent experiments $48 \mathrm{~h}$ later. The sequences used are shown in Supplementary Table 1. All sequences were synthesized by Sangon Biotech (Shanghai, China).

To measure the effect of gene changes on naive $T$ cell differentiation, $1 \times 10^{5}$ breast cancer cells were inoculated into the lower chamber of the coculture chamber and cultured overnight. $1 \times 10^{5} \mathrm{CD} 4 \mathrm{~T}$ cells and CD8 T cells were inoculated into the upper chamber of the coculture chamber and cultured for $48 \mathrm{~h}$. Then, cell stimulation cocktail (plus protein transport inhibitors) (00-4975-03, eBioscience) was inoculated for $6 \mathrm{~h}$, and T cells were collected for subsequent detection. They were grouped into the control, mimic NC, $m i R-520 b$ mimics, inhibitor NC, and miR-520b inhibitor groups.

To observe the polarization of tumor-associated macrophage, breast cancer cells transfected with miR-520b mimics and $m i R-520 b$ inhibitor were cocultured with M0 macrophage and divided into the control, mimic NC, $m i R$ $520 b$ mimics, inhibitor NC, and miR-520b inhibitor groups. 
First, we cultured the human monocyte cell line THP-1 cells. THP- 1 cells were purchased from the ATCC and cultured in RPMI 1640 medium with 10\% heat-inactivated FBS and 1\% penicillin/streptomycin. Then, we induced THP-1-derived macrophages. THP-1 cells were cultured in serum-free RPMI 1640 medium with $100 \mathrm{ng} / \mathrm{mL}$ phorbol 12-myristate 13-acetate. After $48 \mathrm{~h}$ culture, THP-1 cells were cultured in PMA-free RPMI 1640 medium with 10\% FBS and 1\% penicillin/streptomycin for $24 \mathrm{~h}$ to induce M0 macrophage.

2.4. Sorting and Identification of CD4 T Cells and CD8 $T$ Cells. According to previous literature [23], blood samples from breast cancer patients were collected, then mononuclear cells were isolated, and the total number of mononuclear cells was calculated. MagniSort Human CD4 T Cell Enrichment Kit (8804-6811-74, Thermo Fisher) and MagniSort Human CD8 T Cell Enrichment Kit (8804-681274, Thermo Fisher) were used for CD4 T and CD8 T cell magnetic bead sorting according to the instructions. The purity of CD4 T and CD8 T cells was determined by flow cytometry. Firstly, a single-cell suspension of lymphocytes with a concentration of $1 \times 10^{7}$ cells $/ 100 \mu \mathrm{L}$ was prepared in the cell separation buffer. The cells were then placed in a tube. $20 \mu \mathrm{L}$ MagniSort ${ }^{\mathrm{TM}}$ Enrichment Antibody Cocktail was added to the cells. The cells were washed with a cell separation buffer to a volume of $4 \mathrm{~mL}$ and centrifuged at $300 \mathrm{~g}$ for $5 \mathrm{~min}$. The supernatant was discarded, and the cells were completely resuspended to their original volume with a cell separation buffer. $20 \mu \mathrm{L}$ MagniSort ${ }^{\mathrm{TM}}$ Negative Selection Beads were added to cells. Then, we inserted the tube into the magnet until the bottom of the tube was touching the benchtop through the hole in the bottom of the magnet. We picked up the magnet and in a continuous motion poured the supernatant into a new tube. Finally, we removed the tube containing bound cells from the magnet and discarded it. The untouched, negatively selected cells were ready to use in the new tube. When sorting out CD8 T cells, we picked up the magnet and in a continuous motion poured the supernatant into a $15 \mathrm{~mL}$ conical tube. Then, we removed the tube containing bound cells from the magnet. Finally, we removed the tube containing bound cells from the magnet and discarded it. The untouched, negatively selected cells were ready to use in the $15 \mathrm{~mL}$ conical tube. Flow cytometry assay (A00-1-1102, Beckman) was performed to identify CD4 $\mathrm{T}$ and CD8 T cell purity.

2.5. Quantitative Real-Time PCR ( $q R T-P C R)$. qRT-PCR detected hsa-miR-520b, PTEN, Arg-1, and TNF $\alpha$ expressions. To put it simply, total RNA was extracted using the TRIzol method, and the cDNA reverse transcription kit (4368814, Invitrogen, USA) was used to reverse transcript RNA into cDNAs. SYBR Green qPCR Mix (Invitrogen) was applied to detect the relative gene expression on the $\mathrm{ABI}$ 7900 system. $U 6$ and $\beta$-actin were acted as internal reference genes, and the relative gene levels were calculated by $2^{-\Delta \Delta C T}$ method. Table 2 shows primer sequences used in this study.
TABLE 2: The primers used in this study.

\begin{tabular}{|c|c|}
\hline Primer ID & $5^{\prime}-3^{\prime}$ \\
\hline$h s a-m i R-520 b-\mathrm{F}$ & AAAGTGCTTCCTTTTAGAGGG \\
\hline$h s a-m i R-520 b-\mathrm{RT}$ & GCTGTCAACGATACGCTACGTAAC \\
\hline PTEN-F & AATTGGCCGCTGTCACT \\
\hline PTEN-R & GCCCATTCTTTGTTGATAGCCT \\
\hline $\operatorname{Arg}-1-\mathrm{F}$ & GGGTTGACTGACTGGAGAGC \\
\hline $\operatorname{Arg}-1-\mathrm{R}$ & CACATCACACTCTTGTTCTTTAAGT \\
\hline$T N F \alpha-F$ & AGAACTCACTGGGGCCTACA \\
\hline$T N F \alpha-\mathrm{R}$ & GCTCCGTGTCTCAAGGAAGT \\
\hline U6-F & CTCGCTTCGGCAGCACA \\
\hline$U 6-\mathrm{R}$ & AACGCTTCACGAATTTGCGT \\
\hline$\beta$-Actin-F & ACCCTGAAGTACCCCATCGAG \\
\hline$\beta$-Actin-R & AGCACAGCCTGGATAGCAAC \\
\hline
\end{tabular}

2.6. Immunofluorescence (IF). Immune cell marker CD45, $\mathrm{T}$ cell markers $\mathrm{CD} 3, \mathrm{CD} 4$, and $\mathrm{CD} 8$, natural killer cell marker NK1.1, total macrophage marker CD68, and type M2 macrophage marker CD206 expressions in breast tumor and tumor-adjacent tissue were detected by IF. The slices were roasted at $60^{\circ} \mathrm{C}$ for $12 \mathrm{~h}$. The slices were dewaxed to water and heated to repair antigens. Then, sodium borohydride solution was added for $30 \mathrm{~min}$. They were rinsed with water for $5 \mathrm{~min}$. After that, Sudan black dye solution was added for $5 \mathrm{~min}$. $10 \%$ normal serum or $5 \%$ BSA was sealed for $60 \mathrm{~min}$. Then, they were added to appropriately diluted primary antibody CD3 (17617-1AP, 1:50, ProteinTech), CD4 (MA1-146, 1:50, Thermo Fisher), CD8 (MA1-145, 1:50, Thermo Fisher), CD45 (20103-1-AP, 1:50, ProteinTech), NK1.1 (AB242134, 1 : 50, Abcam), CD68 (AB125212, 1:50, Abcam), and CD206 (18704-1-AP, 1:50, ProteinTech) at $4^{\circ} \mathrm{C}$ overnight and rinsed with PBS 5 min for 3 times. The second antibody, rhodamine (TRITC)-conjugated goat anti-rat IgG $(H+L)$ (SA00007-7, ProteinTech) or CoraLite594-conjugated goat anti-rabbit IgG $(H+L)$ (SA00013-4, ProteinTech), was incubated at $37^{\circ} \mathrm{C}$ for $90 \mathrm{~min}$ and washed with PBS $5 \mathrm{~min}$ for 3 times. DAPI working fluid was dyed at $37^{\circ} \mathrm{C}$ for $10 \mathrm{~min}$ and washed with PBS $5 \mathrm{~min}$ for 3 times. Then, we sealed tablets with buffered glycerin. The slices were stored away from light and observed under a fluorescence microscope.

2.7. Starbase Prediction and Dual-Luciferase Reporter Assay. Starbase version 2.0 (http://starbase.sysu.edu.cn/index.php) predicted $P T E N$ and $m i R-520 b$ binding sites [24]. Wild-type (WT) PTEN (5'-UUGAAGAUUUAUGAUGCACUUAU$3^{\prime}$ ) or mutant (MUT) PTEN (5'-UUGAAGAUUUAUGAUCTGAGCAU- $3^{\prime}$ ) fragments were constructed and inserted into the pmirGLO vector (Promega) to verify the binding of PTEN with miR-520b. According to the instructions, the recombinant vector was transfected into the cells using Lipofectamine 3000 reagent (Thermo Fisher Scientific) and mimic NC and miR-520b mimics were simultaneously transferred into the cells. Finally, the NanoGlo double luciferase reporter assay (Promega) was applied to measure luciferase activity. 
2.8. Fluorescence-Activated Cell Sorting (FACS). Cells were resuspended with $500 \mu \mathrm{L} 10 \%$ FBS 1640, supplemented with $1 \mu \mathrm{L}$ Cell Stimulation Cocktail (plus protein transport inhibitors) (00-4975-03, eBioscience). The culture was stimulated at $37^{\circ} \mathrm{C}$ for $6 \mathrm{~h}$. Then, the cells were collected, centrifuged at $350 \mathrm{~g}$ for $5 \mathrm{~min}$, and the supernatant was discarded. $1 \mathrm{~mL} 0.5 \%$ BSA-PBS was added to wash the cells once. The cells were centrifuged at $350 \mathrm{~g}$ for $5 \mathrm{~min}$, and the supernatant was discarded. The resuspended cells were added with $500 \mu \mathrm{L}$ intracellular buffer (88-8824-00, eBioscience), fixed at room temperature for $30 \mathrm{~min}$, and centrifuged at $350 \mathrm{~g}$ for $5 \mathrm{~min}$, and the supernatant was discarded. $1 \mathrm{~mL}$ 1×permeabilization buffer (88-8824-00, eBioscience) was added to resuspend the precipitation and centrifuged at $350 \mathrm{~g}$ for $5 \mathrm{~min}$, and the supernatant was discarded. $100 \mu \mathrm{L} 1 \times$ permeabilization buffer resuspended cell precipitation. CD4 (MA5-16854, eBioscience) $+\mathrm{IFN} \gamma$ (MHCIFG01, eBioscience), CD8 (MA1-12028, eBio science) + IFN $\gamma \quad$ (MHCIFG01, eBioscience), FOXP3 (A18662, eBioscience), CD206 (MA5-16870, eBioscience), and CD68 (MA1-82715, eBioscience) antibodies were incubated at room temperature in dark room for $30 \mathrm{~min}$. At the same time, the nondyeing tube and single dyeing tube are set. The cells were washed with $1 \mathrm{~mL}$ containing $0.5 \%$ BSAPBS once and centrifuged at $400 \mathrm{~g}$ at room temperature for $5 \mathrm{~min}$, then the supernatant was discarded, and the cells were resuspended with $150 \mu \mathrm{L} 0.5 \%$ BSA-PBS and tested on the machine. Tumor tissue was taken and digested with $0.25 \%$ trypsin at $37^{\circ} \mathrm{C}$. Following the above steps, CD4 (MA516854, eBioscience) + IFN $\gamma$ (MHCIFG01, eBioscience), CD3 (MA1-80640, eBioscience), CD4 (MA5-16854, eBioscience), CD8 (MA1-12028, eBioscience), NK1.1 (11-5941-81, eBioscience), FOXP3 (A18662, eBioscience), CD206 (MA516870, eBioscience), and CD68 (MA1-82715, eBioscience) antibodies were added. Then, the proportion of positive cells was detected.

\subsection{Enzyme-Linked Immunosorbent Assay (ELISA). IFN $\gamma$} quantitative ELISA kit (CSB-E04577H, V10034261; CUSABIO) was used to detect IFN $\gamma$ according to the instruction. The concentration of IFN $\gamma$ was calculated using the standard curve provided by Dynatech MR7000 (USA), and the results were expressed as $\mathrm{pg} / \mathrm{ml}$.

2.10. In Vivo Tumorigenesis. Sixty SPF-grade, 5-week-old female $\mathrm{BALB} / \mathrm{c}$ mice were randomly divided into model, inhibitor NC, $m i R-520 b$ inhibitor, $m i R-520 b$ inhibitor + siNC, and $m i R-520 b$ inhibitor + siPTEN groups, with 10 mice in each group. Animal studies were approved by the Medical Ethics Committee of Xiangya Hospital (AF/SQ202104792). Lentiviral vectors $m i R-520 b$ and PTEN were constructed through Sangon Biotech (Shanghai, China) and transfected in mouse breast cancer 4T1 cells. The sequences used are shown in Supplementary Table 1 . For tumor formation, $2 \times 10^{6} 4 \mathrm{~T} 1$ cells were suspended in $200 \mu \mathrm{L}$ PBS. Then, they were injected into the subcutaneous area. Tumor volume and weight were measured in each group at $28 \mathrm{~d}$. Morphological changes of breast cancer tissues were detected by HE staining.
2.11. HE Staining. HE staining was used to detect the morphological changes of breast tumors in mice. The slices were baked at $60^{\circ} \mathrm{C}$ for $12 \mathrm{~h}$. The slices were dewaxed to water, stained with hematoxylin for $1 \mathrm{~min}$, and washed with distilled water. Then, they were returned to blue with PBS, stained with eosin for $5 \mathrm{~min}$, and rinsed with distilled water. All levels of alcohol (95-100\%) were dehydrated for $5 \mathrm{~min}$. After removal, it was placed in xylene for $10 \mathrm{~min}$ and then sealed with neutral gum and observed under the microscope.

2.12. Western Blot (WB). RIPA lysis buffer was used to extract total proteins from cells and tissues according to the instructions, and the protein was quantitated according to the BCA protein assay kit. The loading buffer of SDS-PAGE was mixed, and they were heated in a boiling water bath at $100^{\circ} \mathrm{C}$ for $5 \mathrm{~min}$. The proteins were adsorbed on the PVDF membrane through the gel electrophoresis. A 5\% skim milk solution was used to block at room temperature for $2 \mathrm{~h}$. PTEN (\#9188, $1: 1000$, CST), IFN $\gamma$ (BS3486, $1: 1000$, Bioworld), FOXP3 (ab20034, 1:1000, Abcam), Arg-1 (16001-1AP, $1: 10000$, ProteinTech), TNF $\alpha$ (17590-1-AP, $1: 1000$, ProteinTech), PI3K (ab191606, 1:5000, Abcam), AKT (10176-2-AP, 1:1000, ProteinTech), p-PI3K (ab182651, 1 : 800, Abcam), p-AKT (66444-1-Ig, 1:5000, ProteinTech) primary antibody, and $\beta$-actin (66009-1-Ig, $1: 1000$, ProteinTech) were incubated overnight at room temperature. TBST was washed three times at room temperature, and the second antibody HRP goat anti-mouse IgG (SA00001-1, 1: 5000, ProteinTech) and HRP goat anti-rabbit IgG (SA000012, 1:5000, ProteinTech) were incubated. After ECL exposure, the film was developed in a dark room and exposed with X-ray, and the internal reference was $\beta$-actin.

2.13. Statistical Analysis. GraphPad 8.0 was applied for statistical analysis, and experimental data were expressed as mean \pm standard deviation (SD), which was repeated at least three times. Differences between the two groups were analyzed using the student's $t$-test. One-way analysis of variance (ANOVA) was used for comparison between multiple groups. $P<0.05$ was statistically significant.

\section{Results}

3.1. The Screening of miRNA. We first screened miRNAs in the GEO database GSE45666. In addition, we did the difference analysis between breast cancer and normal groups. All data were normalized. As shown in Figures 1(a) and 1(b), the volcano map and heatmap were drawn. Then, we used Diana to predict miRNAs. The selection score was set as 0.75 . We found that $h s a-$ miR-520b was upregulated in breast cancer (Figure 1(c)). In addition, the networks of $h s a-m i R-520 b$ and PTEN were plotted by Cytoscape (Figure 1(d)). Therefore, we focused on studying hsa-miR-520b regulatory mechanism in breast cancer.

3.2. The Expression of miR-520b Was High and PTEN Was Low in Tumor Tissues, and the Immune Microenvironment Was Changed. In order to verify selected miR-520b and 

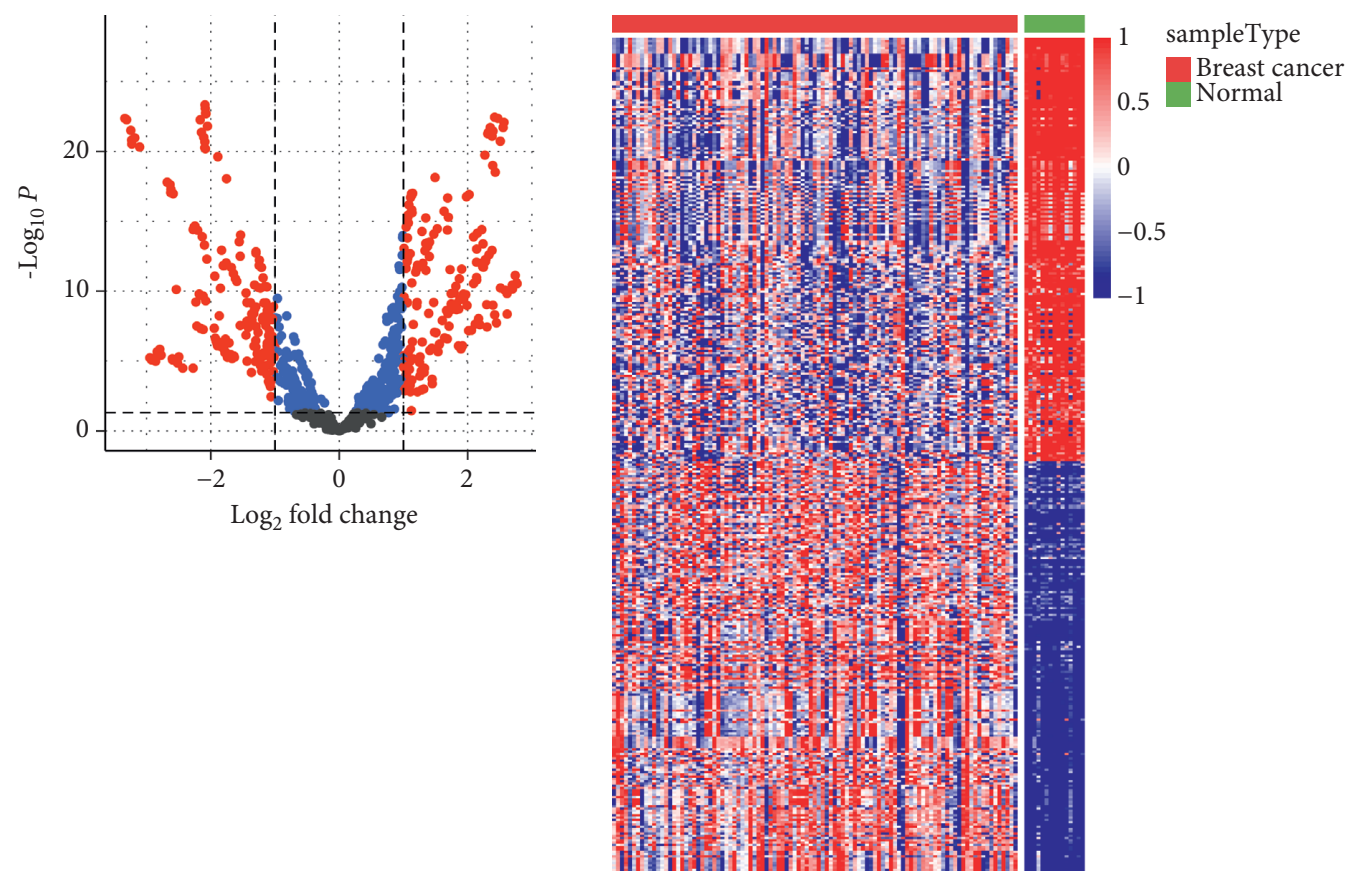

(a)

(b)

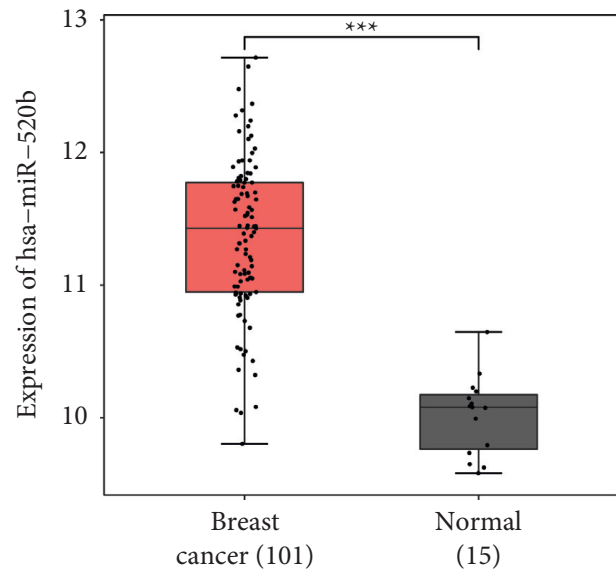

(c)

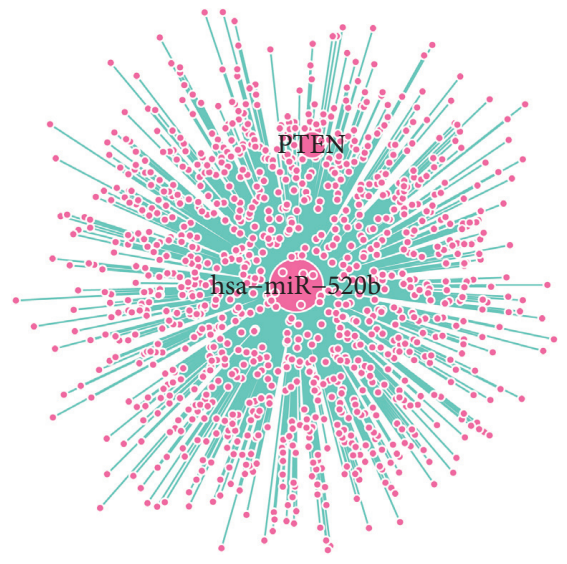

(d)

Figure 1: The screening of miRNA. (a) Volcano map analysis of miRNA differential expression. (b) Differentially expressed miRNA heatmap. (c) hsa-miR-520b expression was high in the breast cancer group compared to the normal group. (d) hsa-miR-520b and PTEN interaction networks. ${ }^{* * *} P<0.001$ vs the normal group.

PTEN expression levels and to detect miR-520b and PTEN expression by qRT-PCR, clinical breast tumor samples and breast cancer cells were taken. Compared with tumor-adjacent tissues, $m i R-520 b$ was highly expressed in breast tumor tissues, while PTEN was low expressed (Figure 2(a)). Compared with mammary epithelial cell line MCF-10A, $m i R-520 b$ was highly expressed in breast cancer cell line MCF-7, while PTEN was low expressed (Figure 2(b)). To investigate whether breast cancer progression was related to immunity, the expression of CD45, CD3, CD4, CD8, and NK1.1 in breast tumor tissues was observed. As shown in Figure 2(c), CD45 immune cells were partially positive in breast tumor tissues, naive T cell marker CD3 was inhibited, and CD4, CD8, and NK1.1 were also inhibited. Further staining for CD206 and CD68 was performed to observe the polarization of breast cancer-associated macrophages. The results showed that CD206 was strongly positive, and CD68 was suppressed in breast tumor tissues compared with adjacent tissue (Figure $2(\mathrm{~d})$ ). These results indicated that $m i R-520 b$ expression was high and PTEN was low in tumor tissues, and T cells and NK cells were inhibited, and macrophages were transformed into M2 type, promoting immune escape.

3.3. miR-520b Bound to PTEN, and during CD4 T Cell Differentiated to Th1 and Treg, Th1 Was Inhibited, and Treg Was Activated. To further explore $m i R-520 b$ and PTEN role in breast cancer, we first used the Starbase to predict the binding site and dual-luciferase reporter assay to prove 

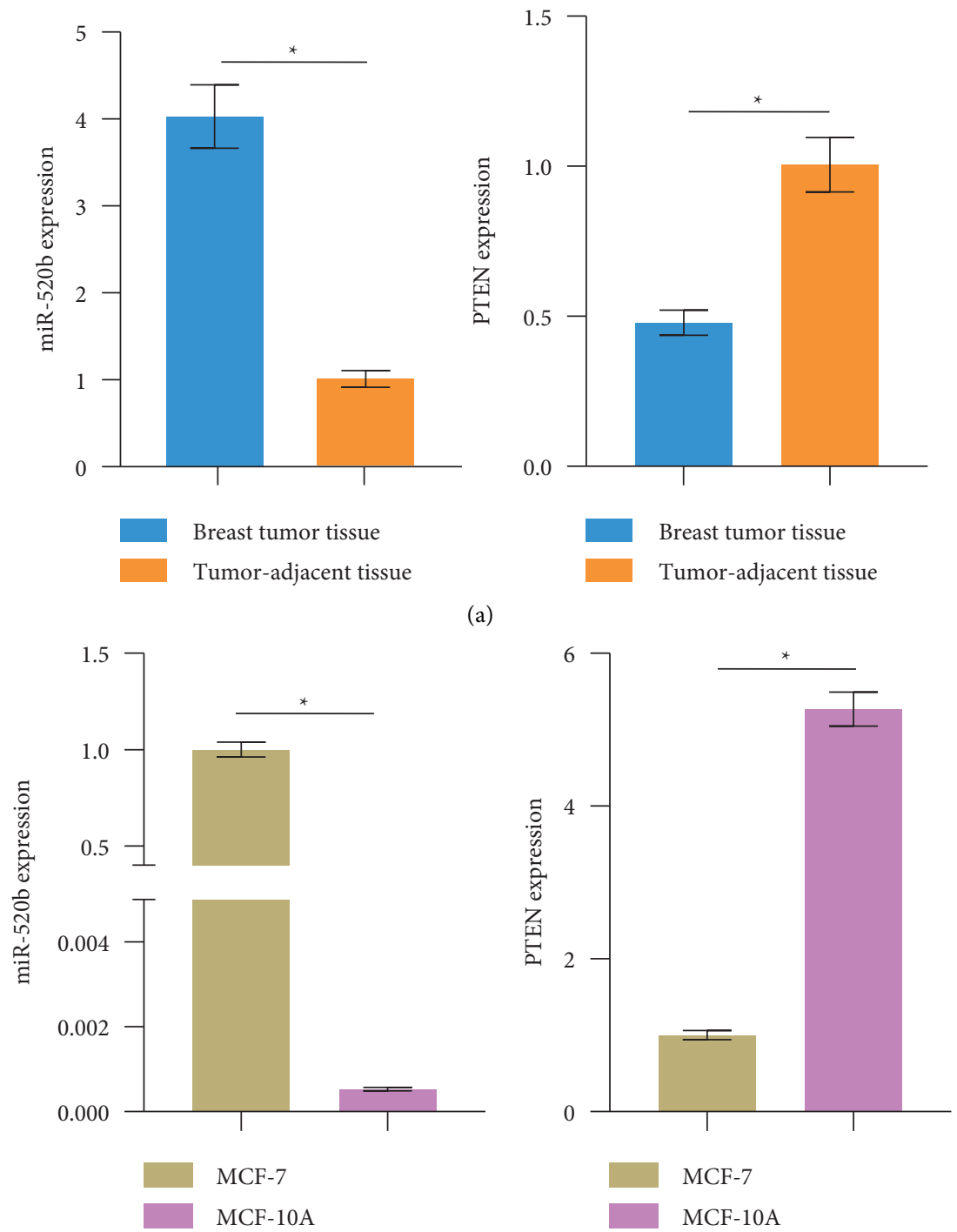

(b)

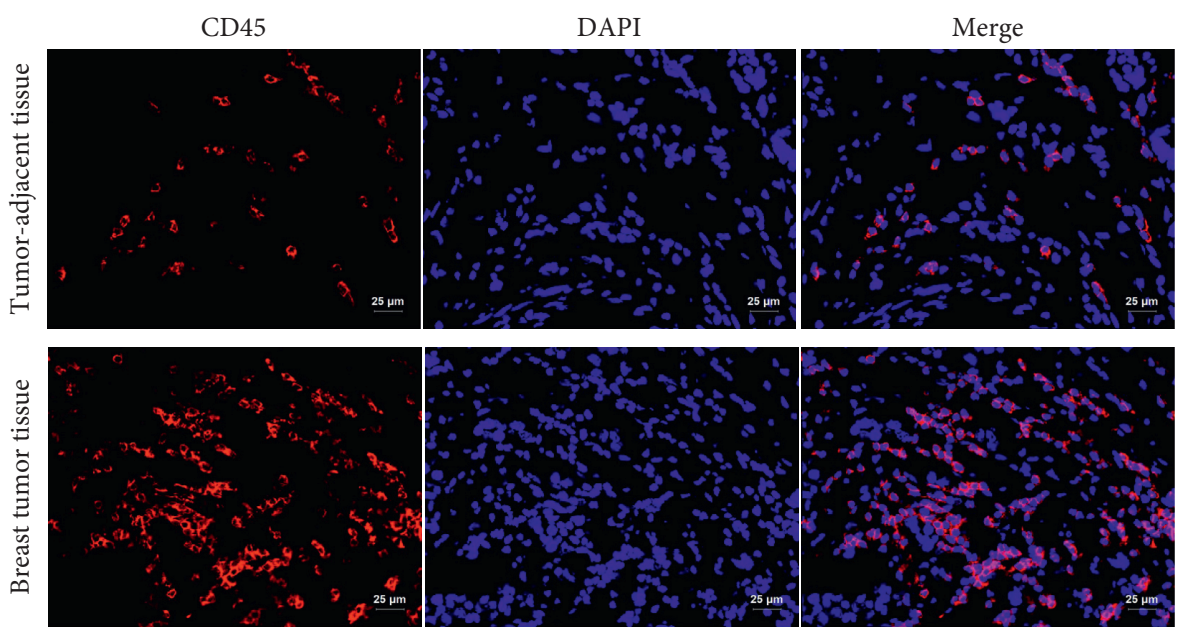

(c)

Figure 2: Continued. 
CD3

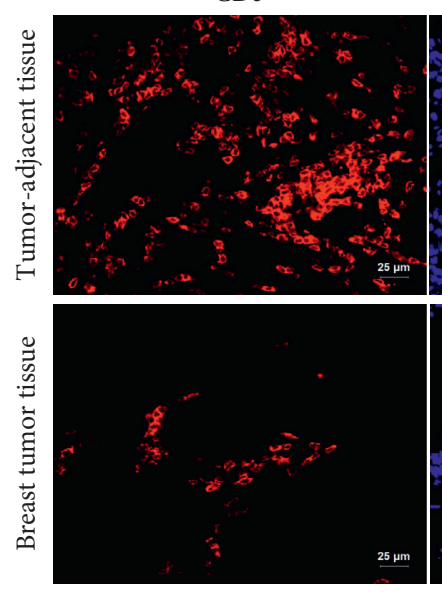

CD4

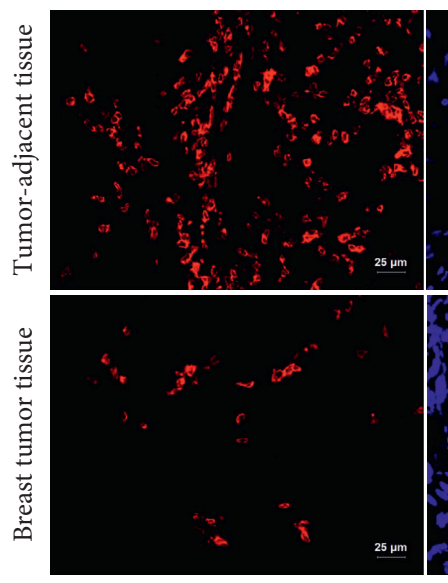

CD8

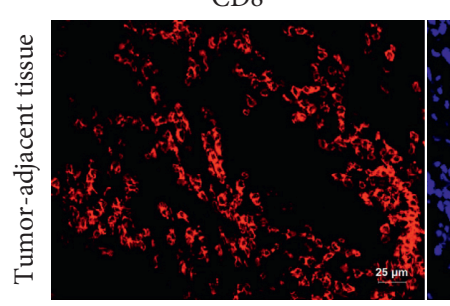

DAPI
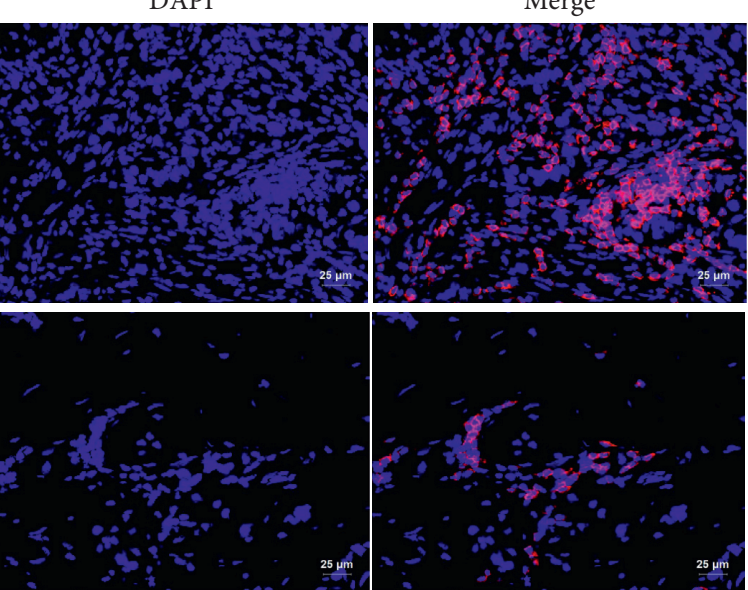

DAPI

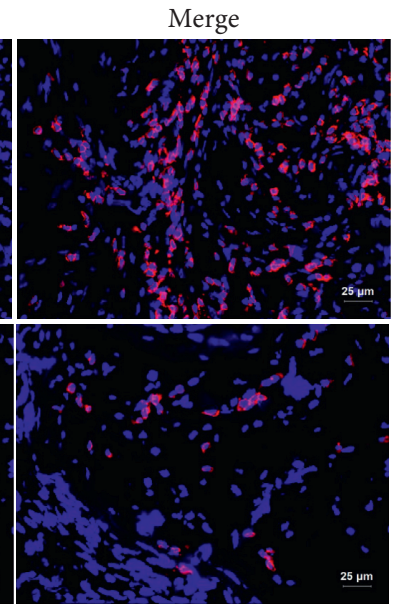

Merge
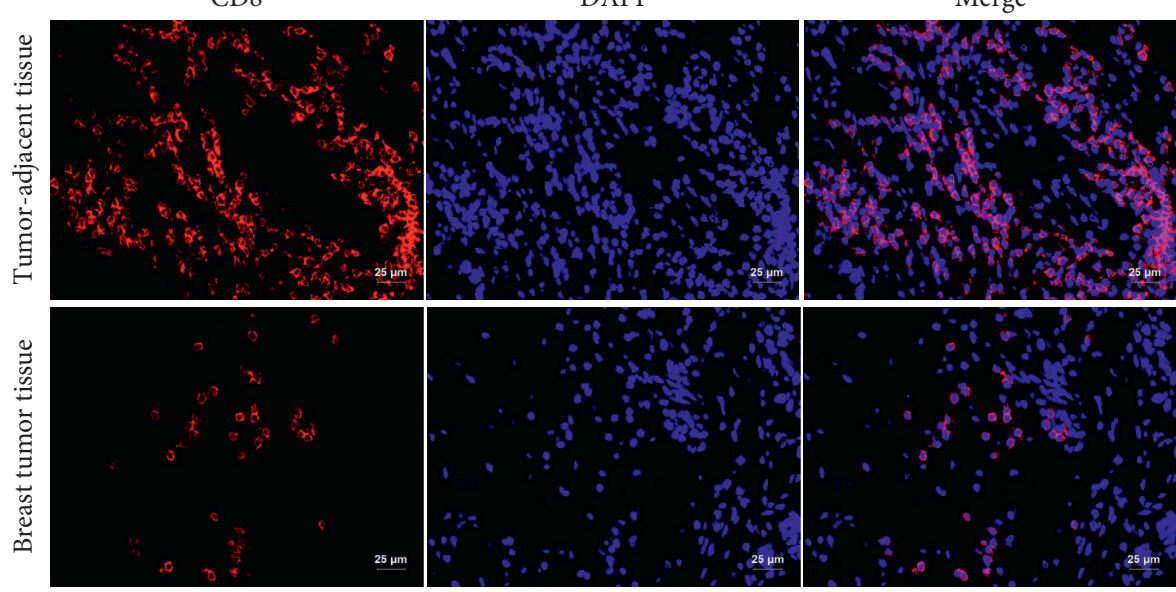

(d)

Figure 2: Continued. 

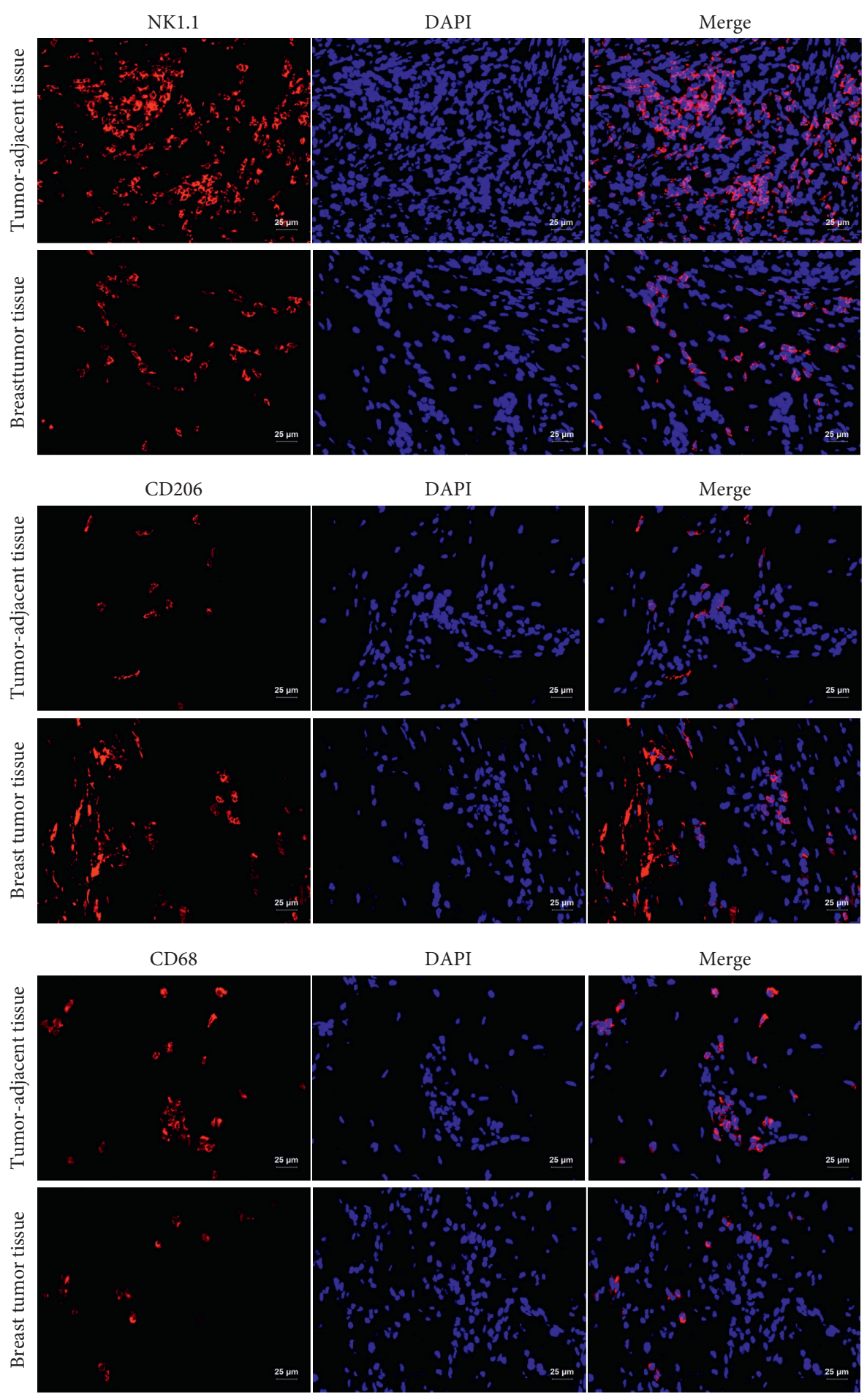

(e)

Figure 2: The expression of miR-520b was high and PTEN was low in tumor tissues, and the immune microenvironment was changed. (a) $m i R-520 b$ and PTEN expressions in tumor tissues were detected by qRT-PCR. Compared with tumor-adjacent tissues, $m i R-520 b$ was highly expressed in breast tumor tissues, and PTEN was low expressed in breast tumor tissues. (b) $m i R-520 b$ and $P T E N$ expressions in breast cancer cells were detected by qRT-PCR. Compared with mammary epithelial cell line MCF-10A, miR-520b was highly expressed in breast cancer cell line MCF-7, and PTEN was low expressed in breast cancer cell line MCF-7. (c) CD45, CD3, CD4, CD8, and NK1.1 expressions in breast tumor tissues were detected by IF. CD45 immune cells were partially positive in breast tumor tissues, naive T cell marker CD3 was inhibited, and CD4, CD8, and NK1.1 were also inhibited. (d) IF detected CD206 and CD68 expression in breast tumor tissues. Compared with adjacent tissue, CD206 was strongly positive and CD68 was suppressed in breast tumor tissues. All experiments were repeated three times; ${ }^{*} P<0.05$; scale bar $=25 \mu \mathrm{m}$; the magnification is 400 times. Differences between the two groups were analyzed using the student's $t$-test. 
the binding of $m i R-520 b$ to PTEN (Figures 3(a) and 3(b)). To measure the effect of gene changes on naive $\mathrm{T}$ cell differentiation, CD4 T cells were cocultured with MCF-7 cells in the Transwell system. As shown in Figure 3(c), splenic CD4 T cells and CD8 T cells were sorted out, and the positive proportions of CD4 T cells and CD8 T cells were both reached $85.27 \%$, indicating that splenic CD4 $\mathrm{T}$ cells and CD8 T cells were successfully sorted. Then, CD4 T cells were counted, and IFN $\gamma$ and FOXP3 were stained to indicate differentiation of Th1 and Treg. Compared with the mimic NC group, the proportion of $\mathrm{CD} 4+\mathrm{IFN} \gamma$ cells decreased and FOXP3 cells increased in $m i R-520 b$ mimics group. The proportion of CD4+IFN $\gamma$ cells increased and FOXP3 cells decreased in miR-520b inhibitor group compared with inhibitor NC group (Figures 3(d) and 3(e); Supplementary Figures 1 and 2). IFN $\gamma$ and FOXP3 expressions were detected in cells cocultured with $\mathrm{CD} 4 \mathrm{~T}$ cells and breast cancer cells. Compared with mimic NC group, IFN $\gamma$ expression was decreased and FOXP3 expression was increased in $m i R$ $520 b$ mimics group. Compared with the inhibitor NC group, IFN $\gamma$ expression was increased and FOXP3 expression was decreased in the miR-520b inhibitor group (Figure 3(f)). Then, CD8 T cells were cocultured with MCF-7 cells in the Transwell system. CD8 T cells were counted and IFN $\gamma$ was stained to characterize the differentiation of Th1. Compared with mimic NC group, the proportion of $\mathrm{CD} 8+\mathrm{IFN} \gamma$ cells decreased in $m i R-520 b$ mimics group. The proportion of $\mathrm{CD} 8+\mathrm{IFN} \gamma$ cells increased in miR-520b inhibitor group compared with inhibitor NC group (Figure 3(g); Supplementary Figure 3). IFN $\gamma$ secretion of CD4 T cells and CD8 T cells was detected by ELISA, and IFN $\gamma$ levels were decreased in $m i R-520 b$ mimics group compared with mimic NC group. IFN $\gamma$ levels were increased in the miR-520b inhibitor group compared with the inhibitor NC group (Figure 3(h)). These results indicated that Th1 was inhibited, and Treg was activated during differentiation of CD4 T cell Th1 and Treg.

3.4. Polarization of Macrophage Associated with Breast Cancer. To observe the polarization of tumor-related macrophages, CD206 and CD68 were stained by flow cytometry to observe the changes in the cells population. The results showed that the proportion of CD206 cells increased and CD68 cells decreased in miR-520b mimics group compared with mimic NC group. Compared with inhibitor NC group, the proportion of CD206 cells decreased and CD68 cells increased in miR-520b inhibitor group (Figures 4(a) and 4(b); Supplementary Figures 4 and 5). Arg-1 and TNF $\alpha$ were characterized by qRT-PCR and WB to verify the polarization trend of macrophages. As shown in Figures 4(c) and 4(d), compared with mimic NC group, Arg-1 expression in miR-520b mimics group was increased and TNF $\alpha$ was decreased. Compared with inhibitor NC group, $m i R-520 b$ inhibitor group showed decreased Arg-1 expression and increased TNF $\alpha$ expression.
3.5. miR-520b Inhibitor Inhibited Tumor Growth and Promoted PTEN Expression. To investigate $m i R-520 b$ and PTEN effects on breast cancer in vivo, we conducted tumorigenesis experiments. Figure 5(a) shows the tumor image of mice. Tumor volume and weight were reduced in the miR-520b inhibitor group compared with the inhibitor NC group. The addition of siPTEN was associated with an increase in tumor volume and weight (Figure 5(b)). Compared with the inhibitor NC group, miR-520b expression was decreased and $P T E N$ expression was increased in the miR-520b inhibitor group. After adding siPTEN, miR-520b expression was increased, and PTEN expression was decreased (Figure 5(c)). To further explore the relationship between $m i R-520 b / P T E N$ and PI3K-Akt pathway, PTEN and PI3K/Akt pathway-related proteins expressions were detected by WB. Compared with the inhibitor NC group, PTEN was increased and $\mathrm{p}-\mathrm{PI} 3 \mathrm{~K}$ and $\mathrm{p}-\mathrm{AKT}$ expressions were decreased in $m i R-520 \mathrm{~b}$ inhibitor group. After adding siPTEN, PTEN expression decreased, and p-PI3K and p-AKT expression increased (Figure 5(d)). HE staining was used to measure the morphological changes of breast cancer tissues. As shown in Figure 5(d), the cytoplasm was stained with eosin to different degrees of red or pink, in sharp contrast to the blue nucleus stained with hematoxylin. The red arrows were used to indicate inflammatory cells. Compared with the inhibitor NC group, the inflammatory infiltration of breast cancer tissue was decreased in the $m i R-520 b$ inhibitor group, while increased after adding siPTEN. These revealed that $m i R-520 b$ inhibitor inhibited tumor growth and promoted PTEN expression, and siPTEN reversed this effect.

3.6. miR-520b Inhibitor Enhanced T Cell Activation in the Tumor Environment and Guided the Polarization of Macrophages to M1, Thereby Inhibiting Tumor Growth. To explore miR-520b inhibitor effect on the number of $\mathrm{T}$ cells and macrophages, CD3, CD4, CD8, NK1.1, CD4+IFN $\gamma$, FOXP3, CD206, and CD68 expressions were detected by flow cytometry. The proportion of CD3, CD4, CD8, and NK1.1 cells increased in $m i R-520 b$ inhibitor group compared to inhibitor NC group. However, the proportion of CD3, CD4, CD8, and NK1.1 cells decreased after the addition of siPTEN (Figure 6(a); Supplementary Figures 6-9). Figure 6(b) reveals the proportion of $\mathrm{CD} 4+\mathrm{IFN} \gamma$ cells increased and FOXP3 cells decreased in the miR-520b inhibitor group compared with the inhibitor NC group. The proportion of $\mathrm{CD} 4+\mathrm{IFN} \gamma$ cells decreased and FOXP3 cells increased after the addition of siPTEN (Supplementary Figures 10 and 11). These results indicated that during CD4 T cells differentiated to Th1 and Treg, Th1 was inhibited, and Treg was activated. To detect the polarization of tumor-related macrophage, flow cytometry was used to stain CD206 and CD68, and the changes in cell population were observed. The results showed that the proportion of CD206 cells decreased and CD68 cells increased in $m i R-520 b$ inhibitor group compared with inhibitor NC group. However, the proportion of CD206 cells increased and CD68 cells decreased after the addition of siPTEN (Figure 6(c); Supplementary Figures 12 and 13). These findings suggested that miR-520b inhibitor 


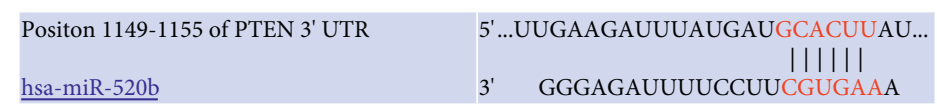

(a)

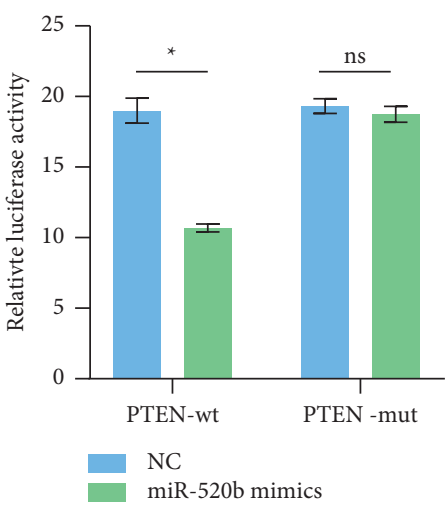

(b)
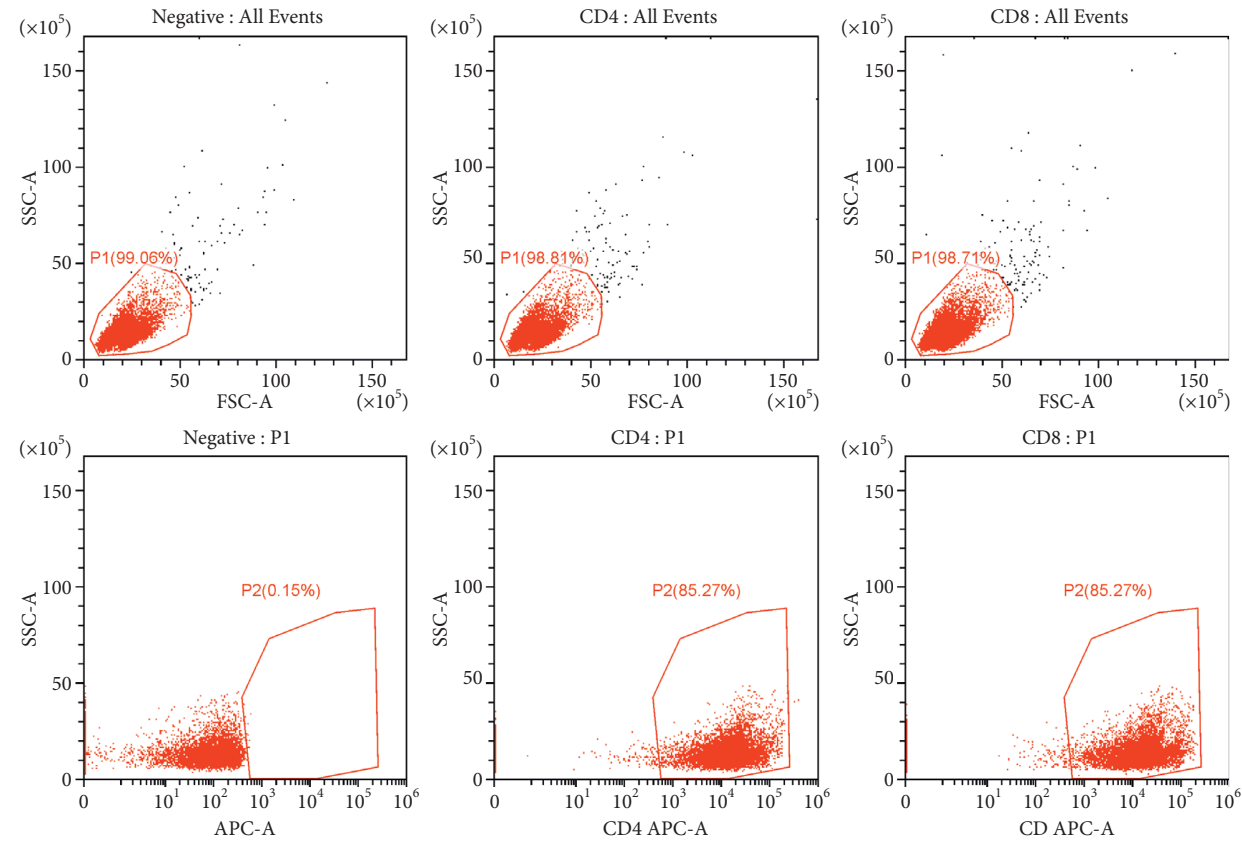

(c)

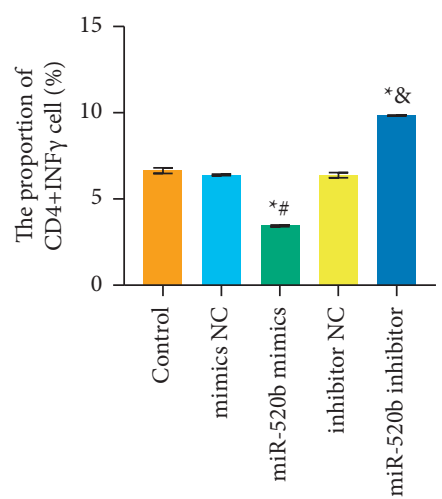

(d)

FIgUre 3: Continued. 


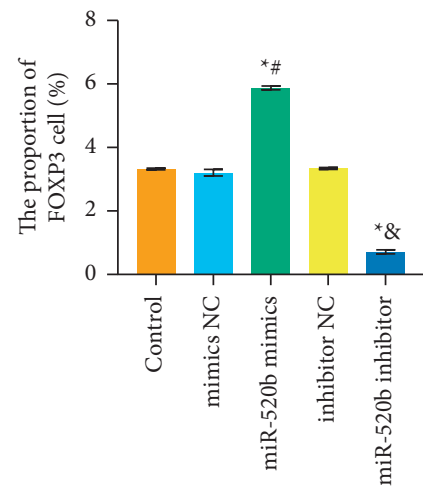

(e)
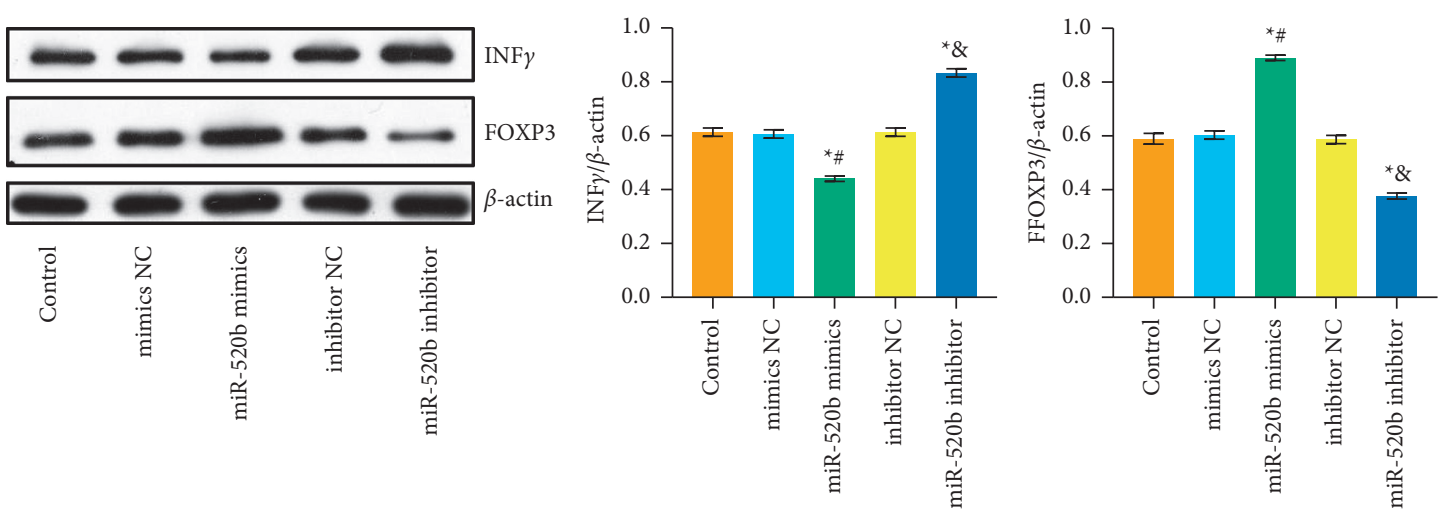

(f)

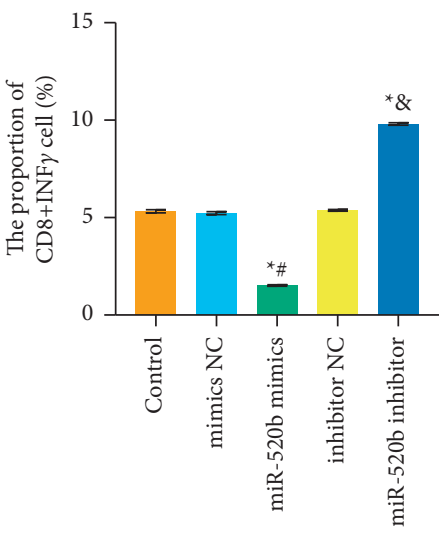

(g)

Figure 3: Continued. 


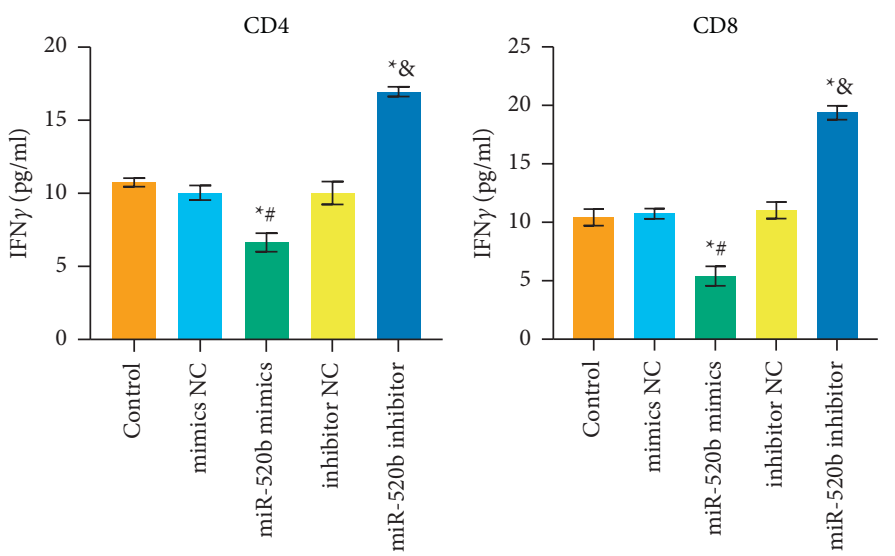

(h)

Figure 3: $m i R-520 b$ bound to PTEN, and during CD4 T cell differentiated to Th1 and Treg, Th1 was inhibited, and Treg was activated. (a) The prediction of $m i R-520 b$ and PTEN binding sites. (b) The binding of $m i R-520 b$ to PTEN was verified by dual-luciferase reporter assay. ${ }^{*} P<0.05$ vs the NC group. ns, no significance. (c) Sorting and identification of spleen derived CD4 T cells and CD8 T cells. The positive proportions of CD4 T cells and CD8 T cells were both reached $85.27 \%$. (d) The proportion of CD4+IFN $\gamma$ cells. (e) The proportion of FOXP3 cells. Compared with the mimic NC group, the proportion of CD4+IFN $\gamma$ cells decreased and FOXP3 cells increased in miR-520b mimics group, while the proportion of CD4+IFN $\gamma$ cells increased and FOXP3 cells decreased in miR-520b inhibitor group compared with inhibitor NC group. (f) IFN $\gamma$ and FOXP3 expressions were verified by WB. Compared with mimic NC group, IFN $\gamma$ expression was decreased and FOXP3 expression was increased in $m i R-520 b$ mimics group. Compared with the inhibitor NC group, IFN $\gamma$ expression was increased and FOXP3 expression was decreased in the $m i R-520 b$ inhibitor group. (g) The proportion of CD8+IFN $\gamma$ cells. Compared with mimic NC group, the proportion of CD8+IFN $\gamma$ cells decreased in $m i R-520 \mathrm{~b}$ mimics group. The proportion of CD8+IFN $\gamma$ cells increased in $m i R-520 b$ inhibitor group compared with inhibitor NC group. (h) ELISA detected IFN $\gamma$ levels. IFN $\gamma$ levels were decreased in miR-520b mimics group compared with mimic NC group. IFN $\gamma$ levels were increased in the $m i R-520 b$ inhibitor group compared with the inhibitor NC group. All experiments were repeated three times; ${ }^{*} P<0.05$ vs the control group, ${ }^{\#} P<0.05$ vs the mimic NC group, and $P<0.05$ vs the inhibitor NC group. Differences between the two groups were analyzed using the student's $t$-test. One-way analysis of variance (ANOVA) was used for comparison between multiple groups.

enhanced $\mathrm{T}$ cell activation in the tumor environment and guided macrophages to polarization to M1, thereby inhibiting tumor growth, while siPTEN restored the immunosuppressive environment in the tumor.

\section{Discussion}

Breast cancer seriously affects life quality. However, there is a lack of new effective and low-cost treatments. In our paper, we identified differentially expressed $m i R-520 b$ in breast cancer based on bioinformatics analysis. In addition, through verification, we found that miR-520b and PTEN could interact with each other. Based on this, we conducted a large number of experiments; the results revealed miR-520b accelerated breast cancer progression by aggravating immunosuppression through PTEN.

miRNAs can be used as early indicators of dietary and physical activity responses in women with metastatic breast cancer [25]. Studies have shown miR-520b promotes doxorubicin-induced breast cancer cell apoptosis by regulating the PI3K/AKT signaling pathway [26]. Cui et al. reported that $m i R-520 b$ could contribute to complementdependent cytotoxicity in breast cancer cells via directly targeting the $3^{\prime}$ UTR of $C D 46$ [27]. In Xing et al.'s study, they found that circIFI30 promoted triple negative breast cancer progression through the circIFI30/miR-520b-3p/CD44 axis [28]. These findings suggested that $m i R-520 b$ was closely related to breast cancer occurrence and development.
Interestingly, we found that $m i R-520 b$ had binding sites with $P T E N$. However, there are few studies on $m i R-520 b$ and $P T E N$ at present. Our study verified that $m i R-520 b$ could bind with PTEN. Moreover, $m i R-520 b$ inhibitor could inhibit tumor growth, promote PTEN expression, and antagonize PI3K/AKT pathway. This is also the innovation of our research.

The tumor microenvironment (TME) in breast tumors has recently become an important participant in tumor progression [29]. Among them, tumor-associated macrophages (TAMs) are the main component of TME in breast cancer [30]. The immune system is very active in breast cancer and plays a dual role in tumor progression and immune monitoring [31]. Infiltration of immune cells predicts prognosis and response to standard breast cancer therapy [32]. According to the presence of microenvironmental signals, macrophages are polarized into two different phenotypes, classical activated (M1) or activated (M2) macrophages [33]. However, TAMs are very similar to M2 polarization [34]. Li et al. reported that TAM secreted CCchemokine ligand 2 and induced tamoxifen resistance by activating PI3K/Akt/mTOR in breast cancer, and high expression of CC-chemokine ligand 2 was correlated with infiltration of CD163+ macrophages [35]. Our study showed that CD45 immune cells were partially positive in breast tumor tissues, naive $\mathrm{T}$ cell marker $\mathrm{CD} 3$ was inhibited, and CD4, CD8, and NK1.1 were also inhibited. In addition, CD206 was strongly positive and CD68 was suppressed in 


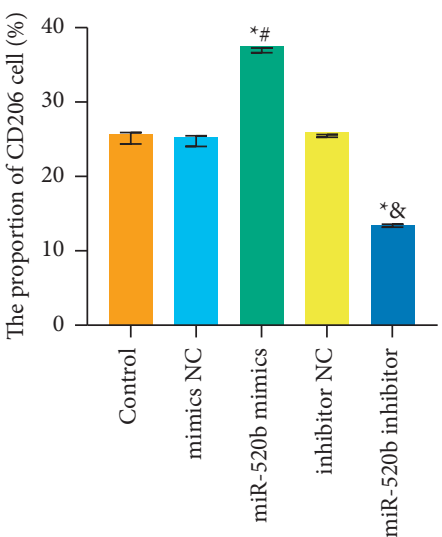

(a)

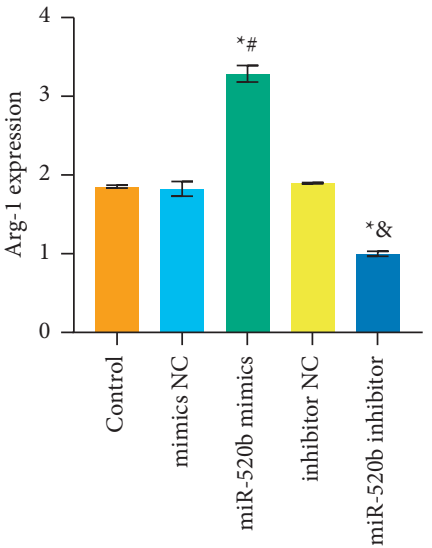

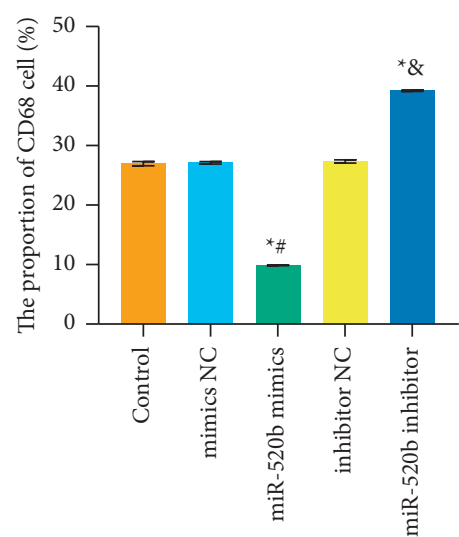

(b)

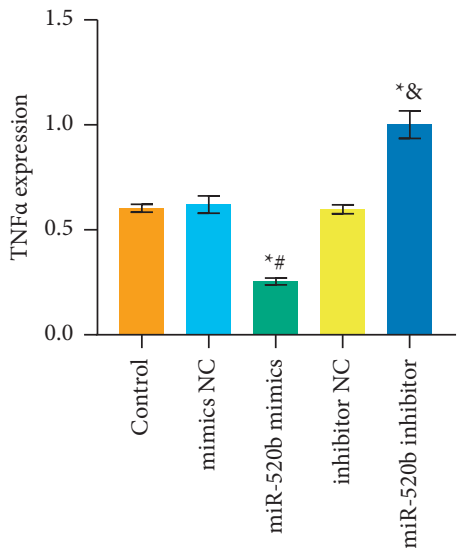

(c)
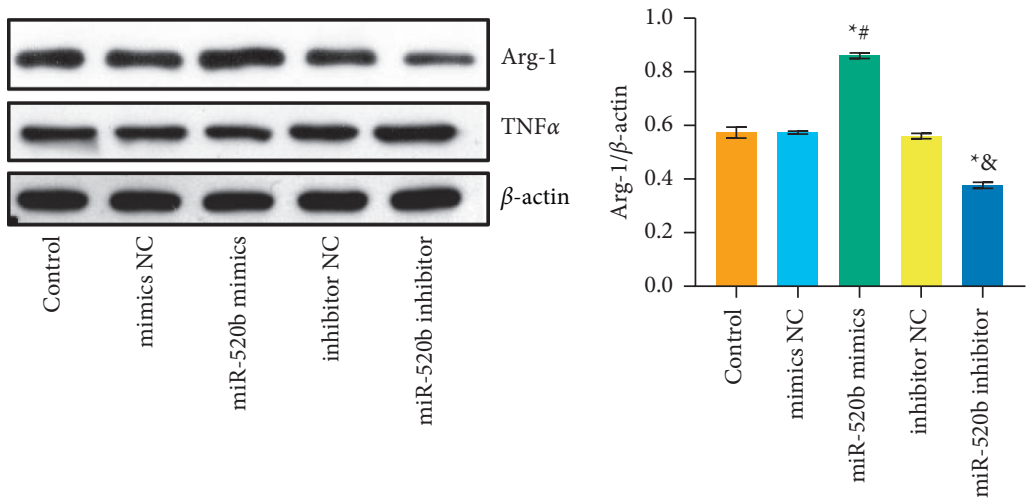

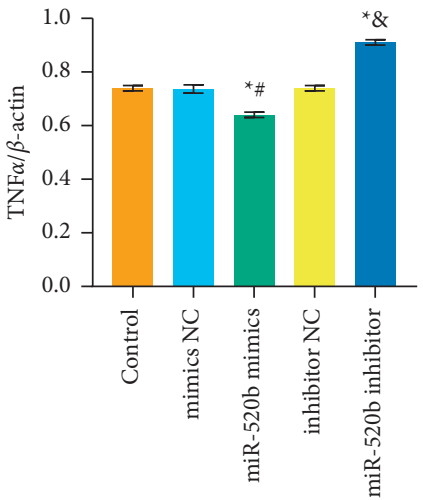

(d)

Figure 4: Polarization of macrophage associated with breast cancer. (a) The proportion of CD206 cells. (b) The proportion of CD68 cells. The proportion of CD206 cells increased and CD68 cells decreased in miR-520b mimics group compared with mimic NC group. Compared with inhibitor NC group, the proportion of CD206 cells decreased and CD68 cells increased in miR-520b inhibitor group. (c, d) qRT-PCR and WB measured Arg-1 and TNF $\alpha$ levels, respectively. Compared with mimic NC group, Arg-1 expression in miR-520b mimics group was increased and TNF $\alpha$ was decreased. Compared with inhibitor NC group, miR-520b inhibitor group showed decreased Arg-1 expression and increased TNF $\alpha$ expression. All experiments were repeated three times; ${ }^{*} P<0.05$ vs the control group, ${ }^{\#} P<0.05$ vs the mimic NC group, and $P<0.05$ vs the inhibitor NC group. Differences between the two groups were analyzed using the student's $t$-test. One-way analysis of variance (ANOVA) was used for comparison between multiple groups.

breast tumor tissue, indicating that the immune microenvironment in the tumor tissue was changed.

Tumor-infiltrating lymphocytes are associated with neoadjuvant chemotherapy response and prognosis in breast cancer [36]. CD4 T cells are essential for maintaining antiviral immunity [37]. CD8 T cells are a vital branch of adaptive immunity, helping to clear intracellular pathogens and provide long-term protection [38]. However, both CD4 and CD8 T cells increase and participate in immune response, showing an obvious dynamic trend in the 


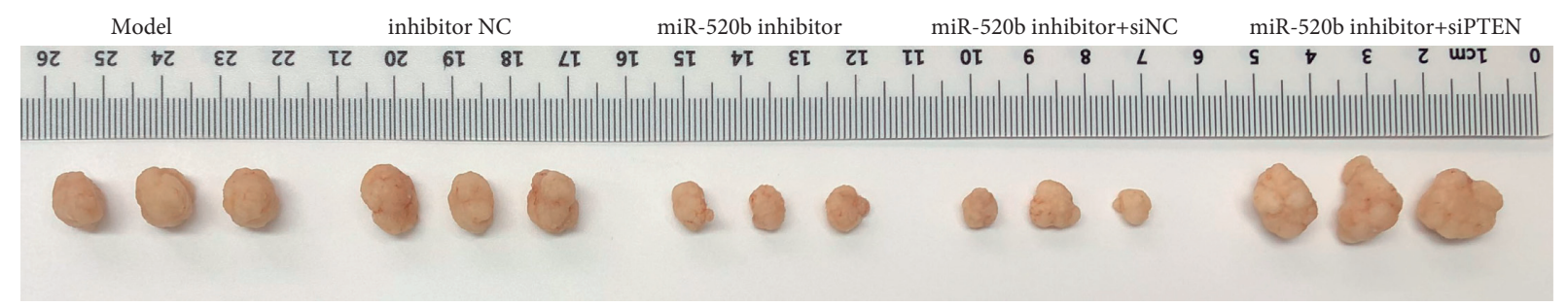

(a)

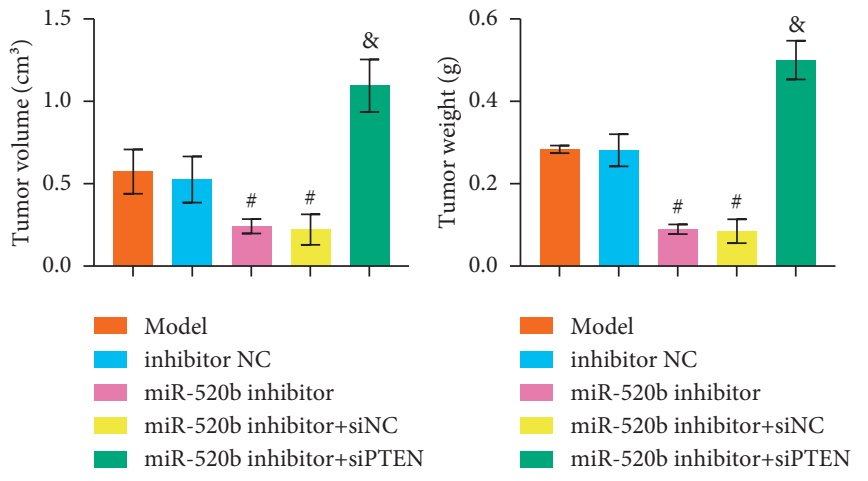

(b)

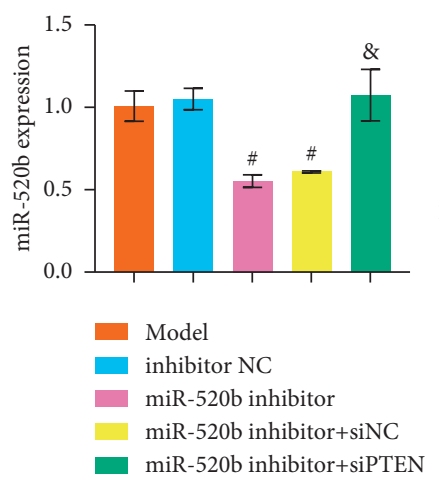

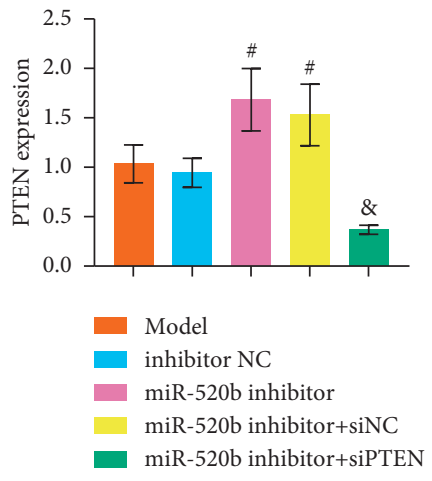

(c)
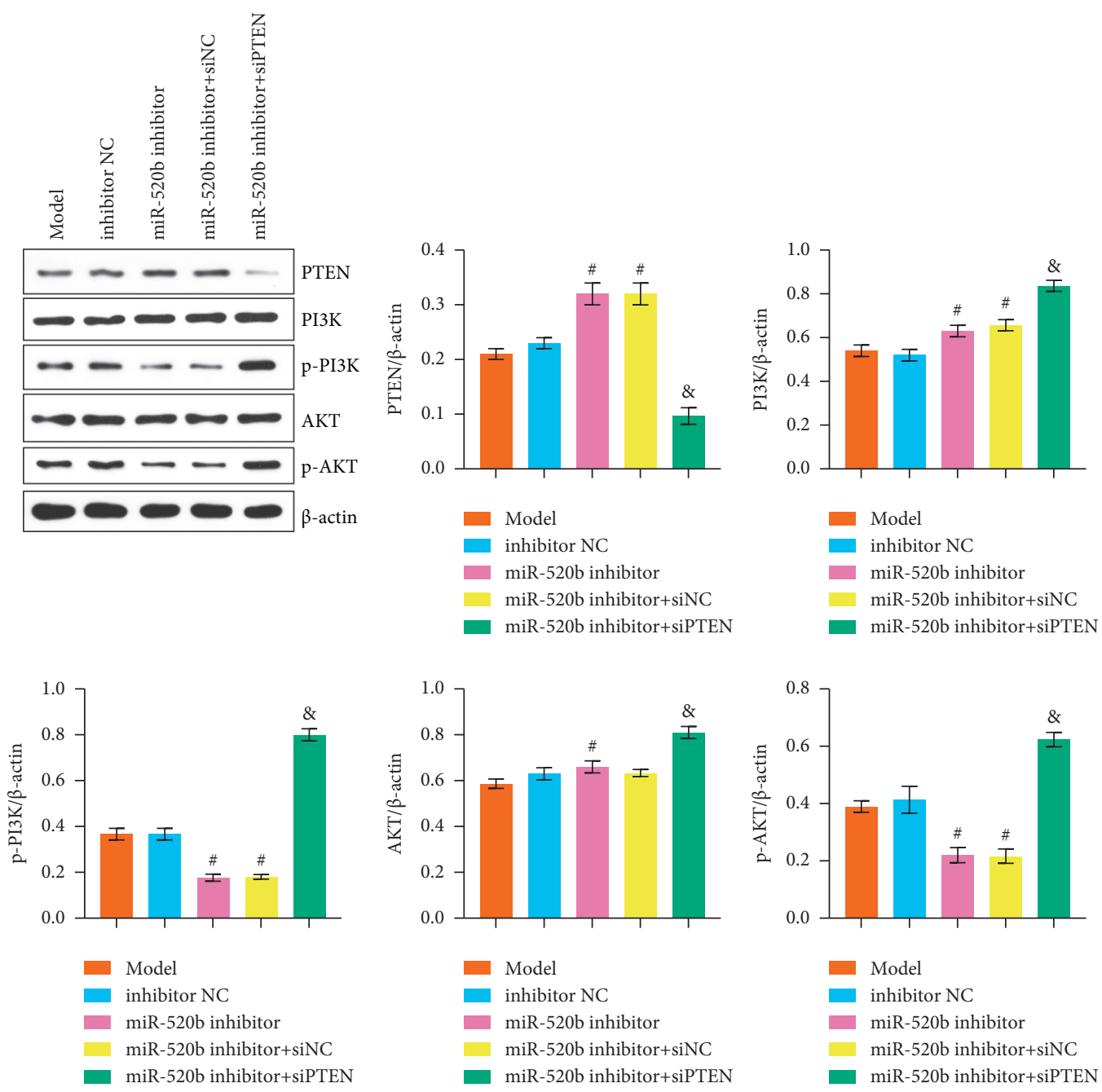

(d)

FIgURE 5: Continued. 

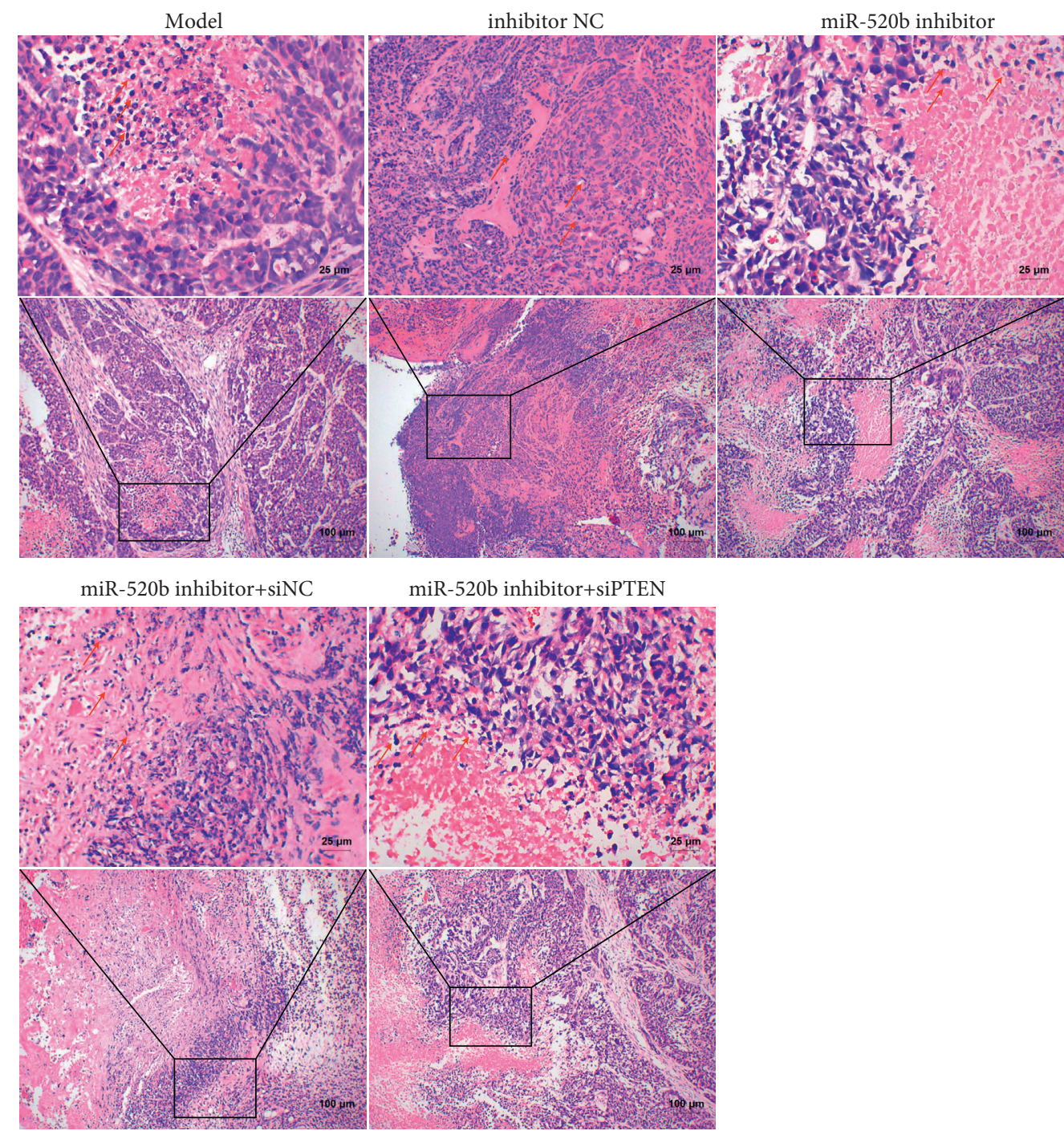

(e)

FIgURE 5: $m i R-520 b$ inhibitor inhibited tumor growth and promoted PTEN expression. (a) Tumor image of mice. (b) Tumor volume and weight in mice. Compared with the inhibitor NC group, tumor volume and weight were reduced in the miR-520b inhibitor group. The addition of $s$ PTEN was associated with an increase in tumor volume and weight. (c) qRT-PCR was performed to detect $m i R-520 b$ and PTEN expressions. (d) PTEN and PI3K/Akt pathway-related protein expressions were detected by WB. Compared with the inhibitor NC group, PTEN was increased and miR-520b, p-PI3K, and p-AKT expressions were decreased in miR-520b inhibitor group. After adding siPTEN, PTEN expression decreased, and miR-520b, p-PI3K, and p-AKT expression increased. (e) HE staining measured morphological changes of breast cancer tissues. The inflammatory infiltration of breast cancer tissue was decreased in the miR-520b inhibitor group, while increased after adding siPTEN. The cytoplasm was stained with eosin to different degrees of red or pink, in sharp contrast to the blue nucleus stained with hematoxylin. The red arrows were used to indicate inflammatory cells. All experiments were repeated three times; ${ }^{\#} P<0.05$ vs the inhibitor NC group, and $P<0.05$ vs the $m i R-520 b$ inhibitor + siNC group. Scale bar $=25 \mu \mathrm{m}$, the magnification is 400 times; scale bar $=100 \mu \mathrm{m}$, the magnification is 100 times. Differences between the two groups were analyzed using the student's $t$-test. One-way analysis of variance (ANOVA) was used for comparison between multiple groups.

development of breast cancer [39]. Th1/Th2 balance is associated with antitumor immunity in breast cancer [40]. Treg cells control tissue homeostasis by fighting local inflammation [41]. Saleh et al. thought tumor Syndecan-1 silencing could enhance ex vivo polarization of CD4+ Th17 and Treg cells of noninflammatory breast cancer [42]. It has been reported that as tumor cells metastasize to lymph nodes and progression of disease stages, the immune response shifts from an inflammatory state to an inhibited state, with a decrease in proinflammatory and antitumor cytokines, IL17 and IFN $\gamma$, and an increase in protumor phenotypes, Th2 and Treg cells [43]. Our results showed that during CD4 T cell differentiated to Th1 and Treg, Th1 was inhibited and Treg was activated. miR-520b inhibitor enhanced the activation of $\mathrm{T}$ cells in the tumor environment, guided the polarization of macrophages to $\mathrm{M} 1$, and changed the immune microenvironment of breast tumors, thereby inhibiting tumor growth. 


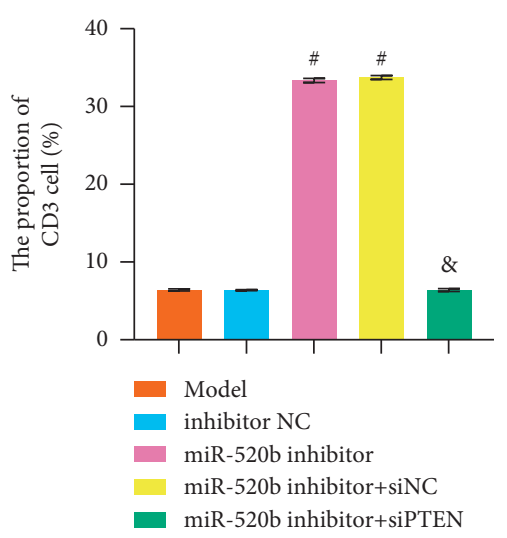

(a)

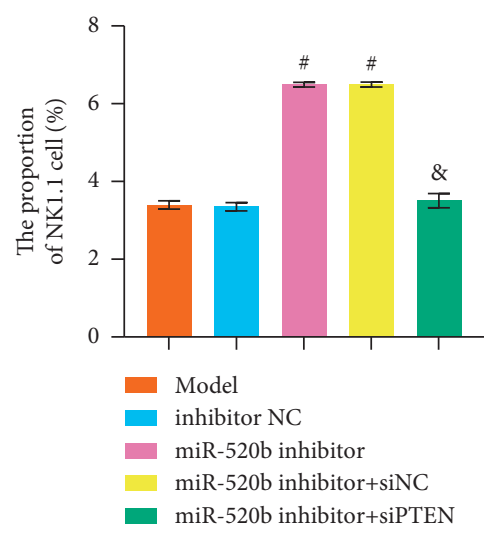

(d)

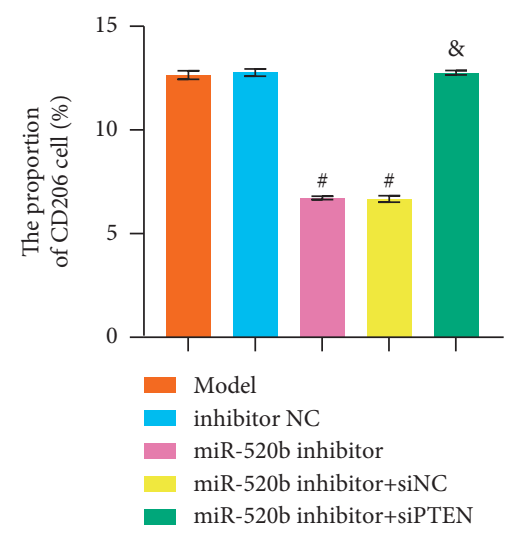

(g)

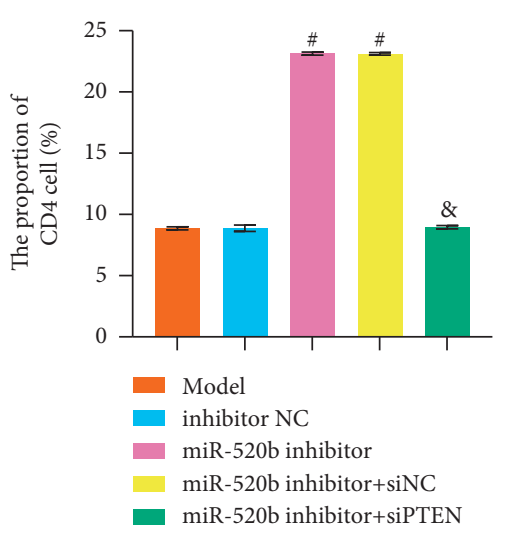

(b)

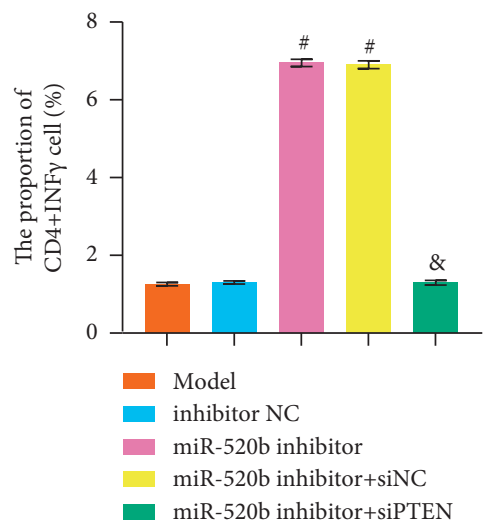

(e)

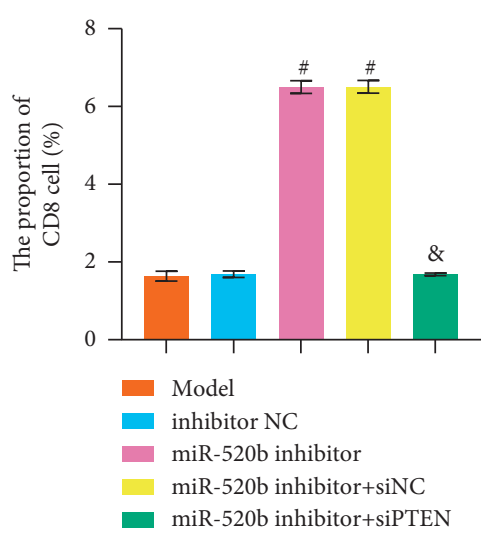

(c)

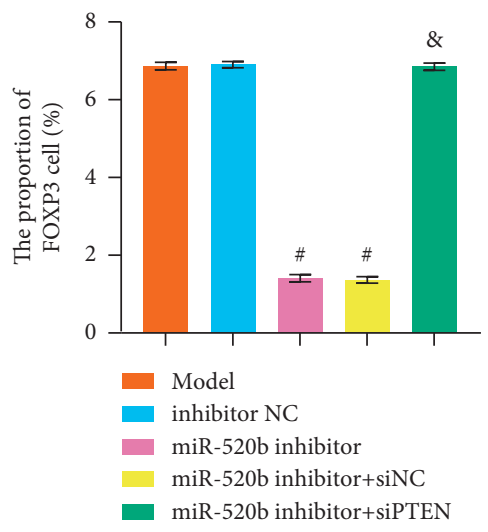

(f)

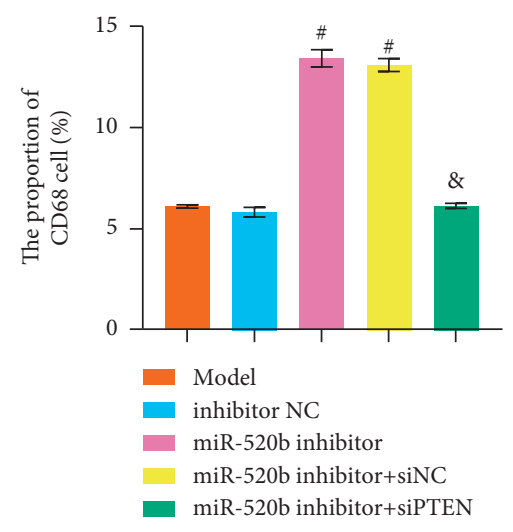

(h)

FIGURE 6: $m i R-520 b$ inhibitor enhanced T cell activation in the tumor environment and guided the polarization of macrophages to M1, thereby inhibiting tumor growth. (a) The proportion of CD3, CD4, CD8, and NK1.1 cells. (b) The proportion of CD4+IFN $\gamma$ and FOXP3 cells. (c) The proportion of CD206 and CD68 cells. The proportion of CD3, CD4, CD8, NK1.1, CD4+IFN $\gamma$, and CD68 cells increased, while FOXP3 and CD206 cells decreased in miR-520b inhibitor group compared with inhibitor NC group. However, the proportion of CD3, CD4, CD8, NK1.1, CD4+IFN $\gamma$, and CD68 cells decreased, while FOXP3 and CD206 cells increased after the addition of siPTEN. All experiments were repeated three times; ${ }^{\#} P<0.05$ vs the inhibitor NC group, and $P<0.05$ vs the miR-520b inhibitor + siNC group. Differences between the two groups were analyzed using the student's $t$-test. One-way analysis of variance (ANOVA) was used for comparison between multiple groups.

However, there are some limitations to our article. Our research is not deep enough, and we need to study further the effect of $m i R-520 b$ and PTEN on macrophage polarization and $\mathrm{T}$ Cell Immunity in breast cancer in the future. We only used the GSE45666 dataset to discriminate miRNA expression differences between adjacent normal and tumor tissues of breast cancer. Next, we will select multiple data datasets for screening. In addition, the coculture cell ratio used in the experiment was $1: 1$. Although preexperimental screening was carried out, multiple dilution ratios should be 
selected for comparative study. In the future, we would like to further study the effect of miR-520b and PTEN on macrophage polarization and $\mathrm{T}$ cell immune in the ratio of 1 : 5 and $1: 10$.

\section{Conclusions}

In brief, our results suggested miR-520b accelerated breast cancer progression by aggravating immunosuppression through PTEN. This paper provided targets for clinical treatment and prognosis judgment of breast cancer and helped to enrich novel treatment strategies for breast cancer.

\section{Data Availability}

The data used to support the findings of this study are available from the corresponding author upon request.

\section{Conflicts of Interest}

The authors declare that there are no conflicts of interest regarding the publication of this paper.

\section{Acknowledgments}

The authors would like to thank the Xiangya Hospital, Central South University, for their technical assistance.

\section{Supplementary Materials}

Supplementary Table 1. The sequence details of mimics and inhibitors used in this study. Supplementary Figure 1. The complete panel of the proportion of $\mathrm{CD} 4+\mathrm{IFN} \gamma$ cells. The groups were divided into the control, mimic NC, $m i R-520 b$ mimics, inhibitor NC, and miR-520b inhibitor groups. Compared with the mimic NC group, the proportion of $\mathrm{CD} 4+\mathrm{IFN} \gamma$ cells decreased in $m i R-520 b$ mimics group, while the proportion of CD4+IFN $\gamma$ cells increased in miR-520b inhibitor group compared with inhibitor NC group. Supplementary Figure 2. The complete panel of the proportion of FOXP3 cells. The groups were divided into the control, mimic NC, $m i R-520 b$ mimics, inhibitor NC, and miR-520b inhibitor groups. Compared with the mimic NC group, the proportion of FOXP3 cells increased in miR-520b mimics group. However, the proportion of FOXP3 cells decreased in $m i R-520 b$ inhibitor group compared with inhibitor NC group. Supplementary Figure 3. The complete panel of the proportion of $\mathrm{CD} 8+\mathrm{IFN} \gamma$ cells. The groups were divided into the control, mimic NC, miR-520b mimics, inhibitor NC, and $m i R-520 b$ inhibitor groups. Compared with mimic NC group, the proportion of CD8+IFN $\gamma$ cells decreased in $m i R$ $520 b$ mimics group. The proportion of $\mathrm{CD} 8+\mathrm{IFN} \gamma$ cells increased in $m i R-520 b$ inhibitor group compared with inhibitor NC group. Supplementary Figure 4. The complete panel of the proportion of CD206 cells. The groups were divided into the control, mimic NC, miR-520b mimics, inhibitor NC, and miR-520b inhibitor groups. The proportion of CD206 cells increased in miR-520b mimics group compared with mimic NC group. Compared with inhibitor $\mathrm{NC}$ group, the proportion of CD206 cells decreased in miR-
$520 b$ inhibitor group. Supplementary Figure 5. The complete panel of the proportion of CD68 cells. The groups were divided into the control, mimic NC, miR-520b mimics, inhibitor NC, and miR-520b inhibitor groups. The proportion of CD68 cells decreased in miR-520b mimics group compared with mimic NC group. Compared with inhibitor NC group, the proportion of CD68 cells increased in miR$520 b$ inhibitor group. Supplementary Figure 6. The complete panel of the proportion of CD3 cells. The groups were divided into the model, inhibitor NC, miR-520b inhibitor, $m i R-520 b$ inhibitor + siNC, and miR-520b inhibitor + siPTEN groups. The proportion of CD3 cells increased in miR-520b inhibitor group compared with inhibitor NC group. However, the proportion of CD3 cells decreased after the addition of siPTEN. Supplementary Figure 7. The complete panel of the proportion of CD4 cells. The groups were divided into the model, inhibitor NC, $m i R$ $520 b$ inhibitor, $m i R-520 b$ inhibitor + siNC, and $m i R-520 b$ inhibitor + siPTEN groups. The proportion of CD4 cells increased in miR-520b inhibitor group compared with inhibitor NC group. However, the proportion of CD4 cells decreased after the addition of siPTEN. Supplementary Figure 8. The complete panel of the proportion of CD8 cells. The groups were divided into the model, inhibitor NC, $m i R$ $520 b$ inhibitor, $m i R-520 b$ inhibitor + siNC, and $m i R-520 b$ inhibitor + siPTEN groups. The proportion of CD8 cells increased in miR-520b inhibitor group compared with inhibitor NC group, while the proportion of CD8 cells decreased after the addition of siPTEN. Supplementary Figure 9. The complete panel of the proportion of NK1.1 cells. The groups were divided into the model, inhibitor NC, $m i R-520 b$ inhibitor, $m i R-520 b$ inhibitor + siNC, and $m i R$ $520 b$ inhibitor + siPTEN groups. The proportion of NK1.1 cells increased in $m i R-520 b$ inhibitor group compared with inhibitor NC group, while the proportion of NK1.1 cells decreased after the addition of siPTEN. Supplementary Figure 10. The complete panel of the proportion of $\mathrm{CD} 4+\mathrm{IFN} \gamma$ cells. The groups were divided into the model, inhibitor NC, miR-520b inhibitor, miR-520b inhibitor + siNC, and miR-520b inhibitor + siPTEN groups. The proportion of CD4+IFN $\gamma$ cells increased in miR-520b inhibitor group compared with inhibitor NC group. However, the proportion of CD4+IFN $\gamma$ cells decreased after the addition of siPTEN. Supplementary Figure 11. The complete panel of the proportion of FOXP3 cells. The groups were divided into the model, inhibitor NC, miR-520b inhibitor, $m i R-520 b$ inhibitor + siNC, and miR-520b inhibitor + siPTEN groups. The proportion of FOXP3 cells decreased in $m i R-520 b$ inhibitor group compared with inhibitor NC group, while the proportion of FOXP3 cells increased after the addition of siPTEN. Supplementary Figure 12. The complete panel of the proportion of CD206 cells. The groups were divided into the model, inhibitor NC, $m i R-520 b$ inhibitor, $m i R-520 b$ inhibitor + siNC, and $m i R$ $520 b$ inhibitor + siPTEN groups. The proportion of CD206 cells decreased in miR-520b inhibitor group compared with inhibitor NC group. However, the proportion of CD206 cells increased after the addition of siPTEN. Supplementary Figure 13. The complete panel of the proportion of CD68 
cells. The groups were divided into the model, inhibitor NC, $m i R-520 b$ inhibitor, $m i R-520 b$ inhibitor + siNC, and $m i R-$ $520 b$ inhibitor + siPTEN groups. The proportion of CD68 cells increased in $m i R-520 b$ inhibitor group compared with inhibitor NC group, while the proportion of CD68 cells decreased after the addition of siPTEN. (Supplementary Materials)

\section{References}

[1] M. Fahad Ullah, "Breast cancer: current perspectives on the disease status," Advances in Experimental Medicine \& Biology, vol. 1152, pp. 51-64, 2019.

[2] K. L. Britt, J. Cuzick, and K.-A. Phillips, "Key steps for effective breast cancer prevention," Nature Reviews Cancer, vol. 20, no. 8, pp. 417-436, 2020.

[3] T. Saha, S. Makar, R. Swetha, G. Gutti, and S. K. Singh, "Estrogen signaling: an emanating therapeutic target for breast cancer treatment," European Journal of Medicinal Chemistry, vol. 177, pp. 116-143, 2019.

[4] E. Kulkoyluoglu-Cotul, A. Arca, and Z. Madak-Erdogan, "Crosstalk between estrogen signaling and breast cancer metabolism," Trends in Endocrinology and Metabolism, vol. 30, no. 1, pp. 25-38, 2019.

[5] S. K. Yeo and J.-L. Guan, "Breast cancer: multiple subtypes within a tumor?” Trends in Cancer, vol. 3, no. 11, pp. 753-760, 2017.

[6] A. G. Waks and E. P. Winer, "Breast cancer treatment: a review," Jama, vol. 321, no. 3, pp. 288-300, 2019.

[7] H. Sabit, E. Cevik, H. Tombuloglu, S. Abdel-Ghany, G. Tombuloglu, and M. Esteller, "Triple negative breast cancer in the era of miRNA," Critical Reviews in Oncology, vol. 157, Article ID 103196, 2021.

[8] X. Li, Z. Zeng, J. Wang et al., "MicroRNA-9 and breast cancer," Biomedicine and Pharmacotherapy, vol. 122, Article ID 109687, 2020.

[9] L. Rask, E. Balslev, R. Søkilde et al., "Differential expression of miR-139, miR-486 and miR-21 in breast cancer patients subclassified according to lymph node status," Cellular Oncology, vol. 37, no. 3, pp. 215-227, 2014.

[10] S. M. M. Yahya and G. H. Elsayed, "A summary for molecular regulations of miRNAs in breast cancer," Clinical Biochemistry, vol. 48, no. 6, pp. 388-396, 2015.

[11] N. Hu, J. Zhang, W. Cui et al., "miR-520b regulates migration of breast cancer cells by targeting hepatitis B X-interacting protein and interleukin-8," Journal of Biological Chemistry, vol. 286, no. 15, pp. 13714-13722, 2011.

[12] H. Zhang, T.-y. Lang, D.-l. Zou et al., "miR-520b promotes breast cancer stemness through Hippo/YAP signaling pathway," OncoTargets and Therapy, vol. 12, pp. 11691-11700, 2019.

[13] C.-Y. Chen, J. Chen, L. He, and B. L. Stiles, "PTEN: tumor suppressor and metabolic regulator," Frontiers in Endocrinology, vol. 9, Article ID 338, 2018.

[14] D. R. Soond, F. Garçon, D. T. Patton et al., "Pten loss in CD4 $\mathrm{T}$ cells enhances their helper function but does not lead to autoimmunity or lymphoma," The Journal of Immunology, vol. 188, no. 12, pp. 5935-5943, 2012.

[15] W. F. Hawse, R. P. Sheehan, N. Miskov-Zivanov et al., "Cutting edge: differential regulation of PTEN by TCR, akt, and FoxO1 controls CD4+ T cell fate decisions," The Journal of Immunology, vol. 194, no. 10, pp. 4615-4619, 2015.
[16] M.-J. Park, S.-J. Moon, E.-J. Lee et al., "Daurinol attenuates autoimmune arthritis via stabilization of nrp1-PTEN-foxp3 signaling in regulatory T cells," Frontiers in Immunology, vol. 10, Article ID 1526, 2019.

[17] K. M. Grzes, M. Swamy, J. L. Hukelmann, E. Emslie, L. V. Sinclair, and D. A. Cantrell, "Control of amino acid transport coordinates metabolic reprogramming in T-cell malignancy," Leukemia, vol. 31, no. 12, pp. 2771-2779, 2017.

[18] W. Peng, J. Q. Chen, C. Liu et al., "Loss of PTEN promotes resistance to T cell-mediated immunotherapy," Cancer Discovery, vol. 6, no. 2, pp. 202-216, 2016.

[19] H. Kishimoto, T. Ohteki, N. Yajima et al., "The Pten/PI3K pathway governs the homeostasis of Valpha14iNKT cells," Blood, vol. 109, no. 8, pp. 3316-3324, 2007.

[20] W. Guo, S. Schubbert, J. Y. Chen et al., "Suppression of leukemia development caused by PTEN loss," Proceedings of the National Academy of Sciences, vol. 108, no. 4, pp. 14091414, 2011.

[21] Y. Li, Y. Liang, T. Ma, and Q. Yang, "Identification of DGUOK-AS1 as a prognostic factor in breast cancer by bioinformatics analysis," Frontiers in Oncology, vol. 10, Article ID 1092, 2020.

[22] D. Pessôa-Pereira, A. F. Evangelista, R. L. Causin et al., "miRNA expression profiling of hereditary breast tumors from BRCA1- and BRCA2-germline mutation carriers in Brazil," BMC Cancer, vol. 20, no. 1, p. 143, 2020.

[23] J. Yang, J. Yan, J. Shao et al., "Immune-mediated antitumor effect by VEGFR2 selective inhibitor for gastric cancer," OncoTargets and Therapy, vol. 12, pp. 9757-9765, 2019.

[24] Q. Dai, J. Deng, J. Zhou et al., "Long non-coding RNA TUG1 promotes cell progression in hepatocellular carcinoma via regulating miR-216b-5p/DLX2 axis," Cancer Cell International, vol. 20 , no. 1 , p. $8,2020$.

[25] J. Olson, P. Sheean, L. Matthews et al., "Circulating miRNAs as early indicators of diet and physical activity response in women with metastatic breast cancer," Future science $O A$, vol. 7, no. 4, Article ID Fso694, 2021.

[26] H. Zhang, X.-D. Zheng, X.-H. Zeng, L. Li, and Q. Zhou, "miR$520 \mathrm{~b}$ inhibits IGF-1R to increase Doxorubicin sensitivity and promote cell apoptosis in breast cancer," Yakugaku Zasshi, vol. 141, no. 3, pp. 415-426, 2021.

[27] W. Cui, Y. Zhang, N. Hu et al., "miRNA-520b and miR-520e sensitize breast cancer cells to complement attack via directly targeting 3'UTR of CD46," Cancer Biology and Therapy, vol. 10, no. 3, pp. 232-241, 2010.

[28] L. Xing, R. Yang, X. Wang et al., "The circRNA circIFI30 promotes progression of triple-negative breast cancer and correlates with prognosis," Aging, vol. 12, no. 11, pp. 10983-11003, 2020.

[29] U. Mehraj, A. H. Dar, N. A. Wani, and M. A. Mir, "Tumor microenvironment promotes breast cancer chemoresistance," Cancer Chemotherapy and Pharmacology, vol. 87, no. 2, pp. 147-158, 2021.

[30] J. Choi, J. Gyamfi, H. Jang, and J. S. Koo, "The role of tumorassociated macrophage in breast cancer biology," Histology and Histopathology, vol. 33, no. 2, pp. 133-145, 2018.

[31] S. Wang, Q. Zhang, C. Yu, Y. Cao, Y. Zuo, and L. Yang, "Immune cell infiltration-based signature for prognosis and immunogenomic analysis in breast cancer," Briefings in Bioinformatics, vol. 22, no. 2, pp. 2020-2031, 2021.

[32] A. Cimino-Mathews, J. B. Foote, and L. A. Emens, "Immune targeting in breast cancer," Oncology, vol. 29, no. 5, pp. 375-385, 2015. 
[33] M. Orecchioni, Y. Ghosheh, A. B. Pramod, and K. Ley, "Macrophage polarization: different gene signatures in M1 (LPS+) vs. Classically and M2 (LPS-) vs. Alternatively activated macrophages," Frontiers in Immunology, vol. 10, Article ID 1084, 2019.

[34] M. Jarosz-Biej, R. Smolarczyk, T. Cichoń, and N. Kułach, "Tumor microenvironment as A "game changer" in cancer radiotherapy," International Journal of Molecular Sciences, vol. 20, no. 13, 2019.

[35] D. Li, H. Ji, X. Niu et al., "Tumor-associated macrophages secrete CC-chemokine ligand 2 and induce tamoxifen resistance by activating PI3K/Akt/mTOR in breast cancer," Cancer Science, vol. 111, no. 1, pp. 47-58, 2020.

[36] S. Meng, L. Li, M. Zhou, W. Jiang, H. Niu, and K. Yang, "Distribution and prognostic value of tumor-infiltrating T cells in breast cancer," Molecular Medicine Reports, vol. 18, no. 5, pp. 4247-4258, 2018.

[37] R. Zander, D. Schauder, G. Xin et al., "CD4+ T cell help is required for the formation of a cytolytic $\mathrm{CD} 8+\mathrm{T}$ cell subset that protects against chronic infection and cancer," Immunity, vol. 51, no. 6, pp. 1028-1042, 2019.

[38] H.-W. Mittrücker, A. Visekruna, and M. Huber, "Heterogeneity in the differentiation and function of CD8+ T cells," Archivum Immunologiae et Therapiae Experimentalis, vol. 62, no. 6, pp. 449-458, 2014.

[39] Y. Huang, C. Ma, Q. Zhang et al., "CD4+ and CD8+ T cells have opposing roles in breast cancer progression and outcome," Oncotarget, vol. 6, no. 19, pp. 17462-17478, 2015.

[40] X. Zhao, J. Liu, S. Ge et al., "Saikosaponin A inhibits breast cancer by regulating Th1/Th2 balance," Frontiers in Pharmacology, vol. 10, p. 624, 2019.

[41] S. Kälin, M. Becker, V. B. Ott et al., "A stat6/pten Axis links regulatory T cells with adipose tissue function," Cell Metabolism, vol. 26, no. 3, pp. 475-492, 2017.

[42] M. E. Saleh, R. Gadalla, H. Hassan et al., "The immunomodulatory role of tumor Syndecan-1 (CD138) on ex vivo tumor microenvironmental CD4+ T cell polarization in inflammatory and non-inflammatory breast cancer patients," PLoS One, vol. 14, no. 5, Article ID e0217550, 2019.

[43] Z. Faghih, N. Erfani, M. R. Haghshenas, A. Safaei, A.-R. Talei, and A. Ghaderi, "Immune profiles of CD4+ lymphocyte subsets in breast cancer tumor draining lymph nodes," Immunology Letters, vol. 158, no. 1-2, pp. 57-65, 2014. 